\title{
GEOGRAPHICAL FREQUENCY OF TROUGHS AND RIDGES ON MEAN 700-MB. CHARTS
}

\author{
WILLIAM H. KLEIN AND JAY S. WINSTON \\ Extended Forecast Section, U. S. Weather Bureau, Washington, D. C. \\ [Manuscript Received July 7, 1958; Revised July 30, 1958] \\ ABSTRACT
}

\begin{abstract}
The geographical frequencies of occurrence of troughs and ridges on both 5-day and 30-day mean 700-mb. charts for the Northern Hemisphere during a long period of record are presented for individual months. Many regions of maximum and minimum frequency show a close relationship to trough and ridge positions on long-period mean, or normal 700-mb. charts. However, even a cursory inspection of these frequency charts shows that they yield considerably more information for both the practicing forecaster and the research worker than can be derived solely from normal maps. Preferred trough and ridge locations and their seasonal changes appear to be related largely to landsea boundaries with their associated thermal influences and also to prominent orography.
\end{abstract}

\section{INTRODUCTION}

It is generally recognized that the major troughs and ridges of the planetary wave pattern have climatologically preferred regions of occurrence. These regions are directly or indirectly related to the geographical distribution of prominent mountain barriers as well as to thermal and frictional influences associated with land and water surfaces. The preference for these regions is so pronounced that in many areas the trough and ridge locations are clearly delineated on long-period mean, or "normal," charts of height at mid-tropospheric levels.

However, the normal chart can only begin to answer the question as to the likelihood of a trough or ridge occurring in a given geographical area, for mean heights do not uniquely define the actual frequency distribution of troughs and ridges. This distribution can be obtained only by summarizing the observed frequencies from the historical file of upper-air charts. The value of such information in supplementing long-period normal maps at the $700-\mathrm{mb}$. level has been demonstrated by one of the authors for both monthly mean [8] and daily [9] charts. Some work along these lines has also been published for daily 500-mb. charts by Austin et al. [1], Dammann [6], and Essenwanger [7].

The scope of all previous studies, however, has been limited to either a small part of the hemisphere, a short period of record, or a few months of the year. A project was therefore initiated a few years ago to extend the previous work on trough-ridge frequency to each month of the year, and also to as large a portion of the Northern Hemisphere and as long a period of record as the availability of data would permit.

The principal results of this project are presented in figures $1-48$, which are grouped by months. These frequency charts are consulted regularly as climatological background information in the preparation of extended forecasts for both 5- and 30-day periods [12]. In addition, they can furnish valuable clues for the short-range forecaster, and for the theoretician in his attempts to explain the dynamics of the general circulation.

\section{DERIVATION AND PRESENTATION OF DATA}

The charts used in this project were 5-day mean maps (prepared twice a week) and 30-day mean maps (prepared once a month) at the 700-mb. level, obtained from the files of the Extended Forecast Section of the U. S. Weather Bureau. The starting point for the 5-day mean data was chosen as September 1946, when a reasonably complete coverage of good data for most of the hemisphere became available. To obtain as many cases as possible, 30-day mean maps were included which have been extended back to October 1932 by judicious extrapolation of surface observations in North America, the Atlantic, and the Pacific [12]. In all cases the latest date used was August 31,1955 . Thus in areas with complete and uninterrupted data coverage, such as the United States, this study is based upon 9 years of record for the 5-day means and 23 years for the 30-day means (except 22 in September). The exact period of record is indicated in the lower righthand corner of each chart. In most other regions, however, less data were available, and the approximate number of years used in each area is given in table 1 .

TABLE 1.-Number of years used in various areas for compiling data on frequencies of mean troughs and ridges

\begin{tabular}{|c|c|c|}
\hline Area & $\begin{array}{l}\text { 5-day } \\
\text { mean }\end{array}$ & $\begin{array}{c}\text { 30-day } \\
\text { mean }\end{array}$ \\
\hline $\begin{array}{l}\text { North America } \\
\text { Atlantic and western Europe } \\
\text { Eastern Pacific } \\
\text { Western Pacific and northeastern Asta } \\
\text { Central and eastern Europe } \\
\text { North Africa } \\
\text { Asla (except northeast) }\end{array}$ & $\begin{array}{r}9 \\
9 \\
9 \\
8-9 \\
7-8 \\
6-9 \\
6-8\end{array}$ & $\begin{array}{r}20-23 \\
19-23 \\
19-23 \\
15-20 \\
8-19 \\
6-21 \\
6-9\end{array}$ \\
\hline
\end{tabular}


In general the results of this report are quite reliable in the region from the east coast of Asia eastward to the west coast of Europe and Africa. In the remainder of the Northern Hemisphere, however, the results (particularly for 30-day means) should be interpreted with caution since complete hemispheric analyses have been available only since 1949. Of course, it is always possible that secular trends or climatic fluctuations in the general circulation, as well as additional data, may modify these results at some future period.

As in previous studies $[8,13]$, troughs were defined as lines connecting the points of minimum latitude reached by the contours (maximum latitude in easterly flow) or, in equivalent form, as lines connecting points of minimum height along latitude circles. ${ }^{1}$ In similar fashion, ridges were defined in terms of maximum height or latitude (minimum latitude in easterly flow). Definition in terms of axes of maximum curvature or vorticity was not attempted because of the difficulties of objective determination. Anyway, on mean maps such axes usually coincide with trough or ridge lines defined in the simple objective manner given above. Trough or ridge lines of all intensities were considered without differentiation, except that minor troughs or ridges, with both intensity (height gradient from trough to ridge along latitude circle) less than 10 feet and lateral extent less than $10^{\circ}$ of latitude, were omitted. The positions of all other troughs and ridges on each 5- and 30-day mean map (regardless of whether in westerly or easterly flow) were recorded to the nearest $10^{\circ}$ of longitude (except $20^{\circ}$ at $70^{\circ} \mathrm{N}$.) along each $10^{\circ}$ latitude circle from $30^{\circ} \mathrm{N}$. to $70^{\circ} \mathrm{N}$. (and also $20^{\circ} \mathrm{N}$. for the 30-day means). The total number of mean charts with troughs or ridges at each standard intersection (e. g., $30^{\circ} \mathrm{N} .-140^{\circ}$ W., $30^{\circ}$ N. $-150^{\circ}$ W., $40^{\circ}$ N. $-140^{\circ}$ W., $40^{\circ}$ N. $-150^{\circ}$ W., etc.) was then tabulated separately for 5 - and 30-day means for all Januarys, all Februarys, etc.

Due to the difference in length of $10^{\circ}$ longitude intervals at high and low latitudes, the frequencies were adjusted to an equivalent basis (unit of $10^{\circ}$ longitude at $50^{\circ} \mathrm{N}$.) by multiplying by the ratio of the cosine of $50^{\circ}$ to the cosine of each latitude. The coefficients used are given in table 2. These adjusted frequencies ${ }^{2}$ were divided by the total number of cases available during each month and then expressed as percentages.

Interpretation of the analyzed fields of trough or ridge frequencies for each month, which are given in figures $1-48$, is relatively straightforward. For example, figure 1 shows the percent of time that troughs were present on 5 -day mean maps within equivalent $10^{\circ}$ arcs of longitude during the 9 Januarys of record. It does not necessarily indicate the number of different troughs that traversed

\footnotetext{
1 The physical significance of troughs defined in this fashion is that they separate areas with southerly geostrophic flow components from areas with northerly flow. The im. portance of meridional flow components in relation to vertical motion and weather has been demonstrated in numerous studies by Miller and others (e. g., [11]).

1 The adjusted frequencles may be somewhat inaccurate at latitudes where the adJusting coefficient of table 2 differs considerably from 1 in regions where the zonal gradient of trough or ridge frequency is nonlinear. A discussion of these errors has been presented olsewhere $[2,10]$. $485868-58-2$
}

TABLE 2.-Size of unit areas in which frequencies of troughs and ridges were tabulated, and coefficients used for adjusting these frequencies to an equal-area basis

\begin{tabular}{|c|c|c|}
\hline Latitude $\left({ }^{\circ}\right.$ N.) & $\begin{array}{c}\text { Width } \\
\text { (olong.) }\end{array}$ & $\begin{array}{l}\text { Adjusting } \\
\text { coefficlent }\end{array}$ \\
\hline $\begin{array}{l}20 \\
40 \\
40 \\
60\end{array}$ & $\begin{array}{l}10 \\
10 \\
10 \\
10 \\
10 \\
20\end{array}$ & $\begin{array}{r}0.68 \\
.74 \\
.84 \\
1.00 \\
1.29 \\
.94\end{array}$ \\
\hline
\end{tabular}

each area, since some troughs may have been located for several weeks within the same $10^{\circ}$ longitude zone. Likewise figure 3 shows the percent of all 5 -day periods in which ridges were located in each longitudinal zone along each latitude circle during January.

Climatological interpretation of the trough and ridge frequencies derived in this study is facilitated by comparison with trough and ridge locations on "normal," or long-period mean maps. For this reason the appropriate monthly normal 700-mb. contours [17] have been superimposed on figures 1-48 as light dotted lines. Although the normal troughs and ridges have not been explicitly delineated, they can be readily located by noting where the contours attain minimum and maximum latitudes.

General inspection of figures 1-48 at once reveals that geographical preferences are more pronounced on the part of 30-day mean troughs and ridges than in the case of their 5-day mean counterparts. This is indicated by the fact that on the 30-day mean charts areas of zero frequency are much more extensive, and centers of maximum frequency are more sharply delineated. As a result the spatial gradients of trough and ridge frequency are considerably stronger in the case of 30-day mean charts. These frequencies were therefore uniformly analyzed at intervals of 10 percent, whereas the 5-day mean frequencies were analyzed at 5 percent intervals (except 10 percent intervals for frequencies greater than 20 percent). Likewise, shading to emphasize areas of high frequency was started at 20 percent for the 30-day means, but at only 15 percent for the 5 -day means.

Aside from these differences, the frequency charts for 5- and 30-day means are generally similar, despite the fact that they were derived from different periods of record. The centers of maximum and minimum frequency are usually located in the same areas on both sets of charts, although the magnitude of the extremes is larger for the 30-day means. Furthermore, the location and orientation of the axes of maximum and minimum frequency correspond closely on the two sets of charts. This lends support to the belief that the large-scale aspects of the frequency charts may be considered as generally stable and reliable features of the general circulation.

For this reason the 5- and 30-day means are discussed jointly in the following summary of the principal features of figures 1-48. For ease of presentation, however, troughs and ridges are considered separately. In the discussion to follow only the highlights are pointed out, 
small-scale features are neglected, and only a few attempts at explaining the reasons for the climatological features are made. Likewise, no effort has been made to relate the trough-ridge frequencies to climatological frequencies of cyclones and anticyclones at sea level [10], although many obvious parallels could be pointed out.

\section{DISCUSSION OF RESULTS}

\section{TROUGHS}

From a hemispheric point of view, the outstanding feature of the charts for trough frequency is the extensive area of maximum frequency in the normal trough in eastern Canada during each month of the year. This area of high frequency extends southward to a position along or off the east coast of the United States in every month except November (also October for the 5-day troughs). However, in the United States another pronounced maximum of troughs is found over the Mississippi Valley and Plains States during many of the non-summer months. In winter the western maximum is in general agreement with calculated positions of orographically produced troughiness (e. g., Charney and Eliassen [5] and Bolin [3]), while the maximum off the east coast appears to be mainly the result of non-adiabatic heating and baroclinic instability (e. g., as suggested by Sutcliffe [16] and Smagorinsky [15]). The locations of maximum trough frequency in eastern Canada and off the east coast of the United States in summer, on the other hand, are not so readily explained, particularly in view of reversals of thermal gradients and weakening of the westerlies. It is probable that these high trough frequencies may be largely quasi-barotropic, downstream consequences of high frequencies of ridges over western Canada and the central United States in summer (to be discussed below).

Between the two trough maxima in the United States region in the cold season there is a relative minimum in trough frequency along the Appalachians or the east coastal plain. This is especially pronounced during the first 4 months of the year and could not have been readily anticipated from the normal contours alone.

The east coast of Asia, like the east coast of North America, is characterized by a trough in the normal contours and a high frequency of troughs observed on 5- and 30-day mean maps. High frequencies are most pronounced between November and April when the maximum area is located over or east of Japan. During the warmer months there is a tendency for the axis of maximum frequency to split, with one branch retreating westward to east Asia and the other appearing in the western Pacific. The latter branch merges with a center of maximum frequency in the Bering Sea, where troughs are frequent all year long, but with highest frequencies in summer.

Another preferred area for troughs throughout the year is the southeastern Pacific, just west of Lower California, where a trough in the normal contours is also present each month. This area of maximum trough frequency is confined to low latitudes during the colder months of the year, but during the warmer season it extends northward along the west coast of the United States. Maximum trough concentration in this region is observed during June, and the maximum of 57 percent in figure 21 is the highest frequency of 5-day mean troughs observed in any portion of the Northern Hemisphere during any month of the year. The quasi-permanent trough along the west coast of North America in summertime has been attributed by Wexler [18] to the marked thermal contrast between cool air over the eastern North Pacific Ocean and heated air over the western plateau.

The west coast of Africa resembles the west coast of Mexico in many respects. During each month a normal trough is present in this region, and observed trough frequency is high. Furthermore, the axis of maximum trough frequency tends to be confined to low latitudes during winter and to extend northward along the coast of Europe during summer. The greatest frequency is reached during July in the case of 30-day mean troughs (fig. 26) and August for 5-day mean troughs (fig. 29).

Another region where low-latitude troughs concentrate tbroughout the year is India-Burma. This is visible chiefly on the 30-day frequencies since they extend souttward to $20^{\circ} \mathrm{N}$. However, a definite duality exists in this maximum frequency area; from February through May the maximum is over the Burma-South China area, while from June through January it is over India-Pakistan. The extension of this trough northward across the Tibetan Plateau is notable on both 5-day and 30-day frequency charts during the summer months and is probably associated with the maximum strength of the Asiatic summer monsoon. Other areas of local trough preference during most of the year are the Black Sea and the Hawaiian Islands. The former displays a pronounced maximum frequency in summer, whicb tends to be on the east side of the sea.

Several areas exhibit very marked seasonal differences. A striking example is the Mediterranean, where troughs are infrequent during the summer months but abundant during the rest of the year. A similar characteristic applies to Alaska, the Gulf of Alaska, Japan, and the Near East. Likewise, in the Great Plains of the United States troughs frequently occur in the lee of the Rocky Mountains during winter and spring, but seldom in summer. The opposite is true in the northern Plateau region of the United States and in Siberia east of Lake Baikal, where troughs are frequent in summer but scarce in winter. Most of these differences can be explained on the basis of thermal reversals and seasonal variations in the latitude and strength of westerlies crossing mountain barriers.

The transition from winter to summer conditions occurs at different times in different areas. For example, the frequency of troughs declines sharply from April to May in Alaska and the Gulf of Alaska, from May to June in central portions of the United States and the Mediterranean, and from June to July over the Japanese Islands 


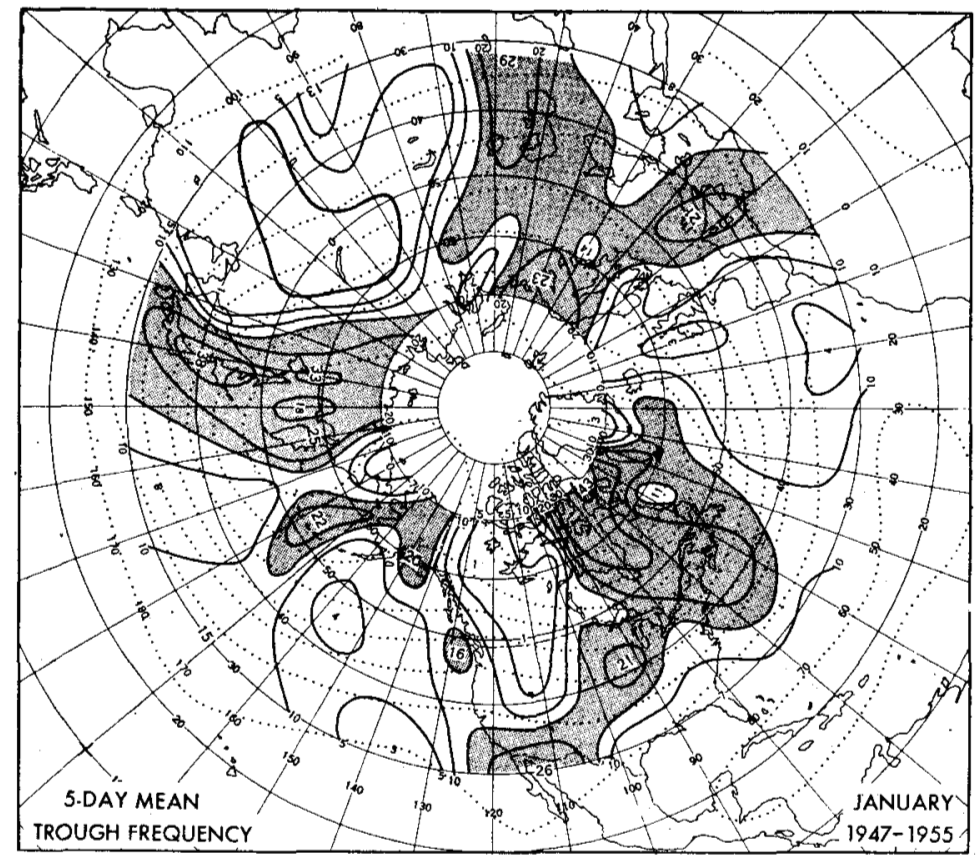

FIGURE 1.

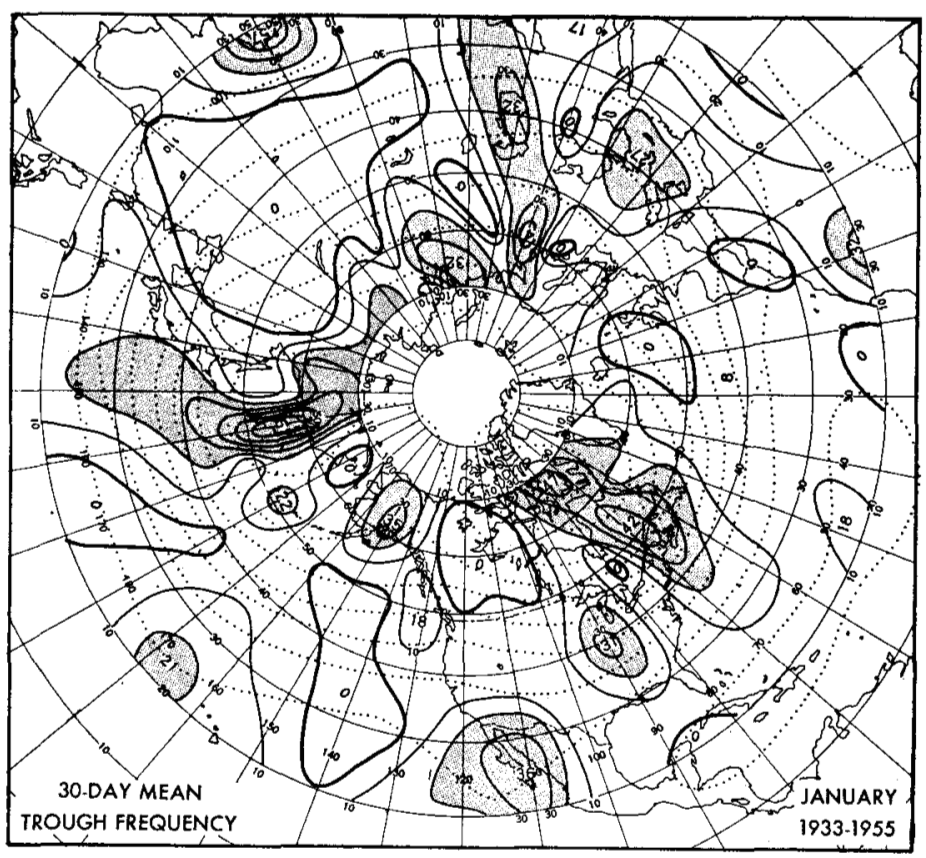

FIGURF 2.

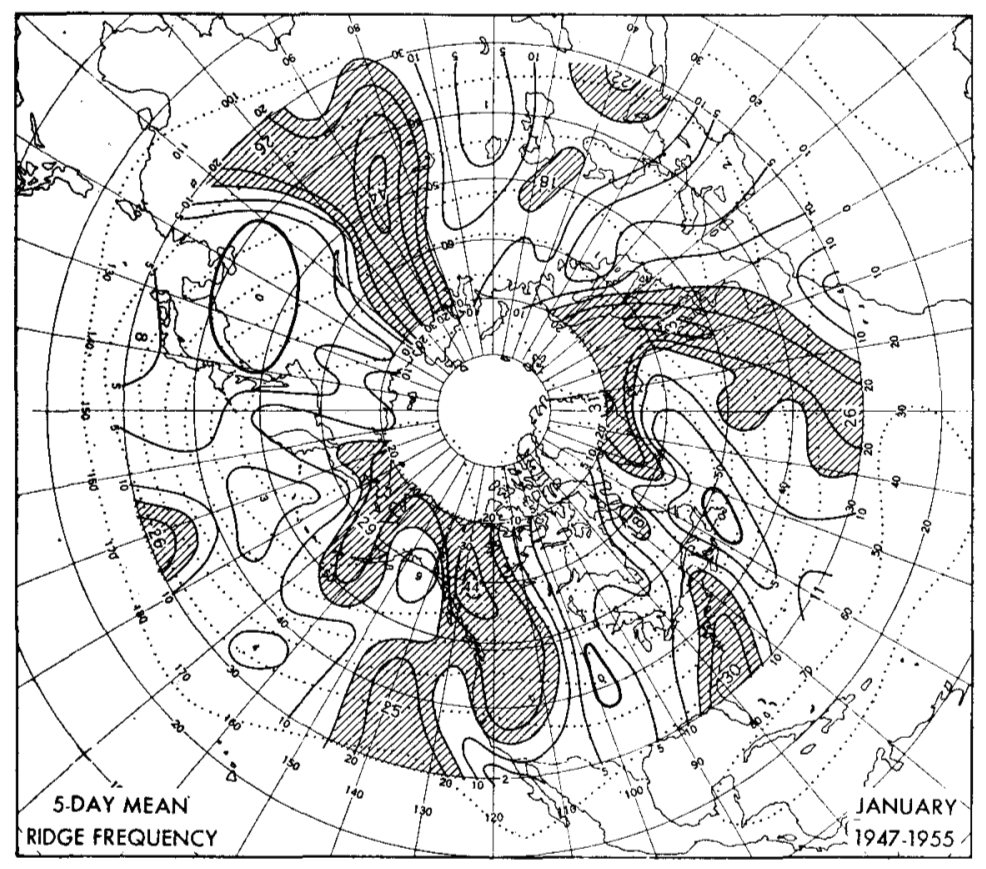

FIGURE 3 .

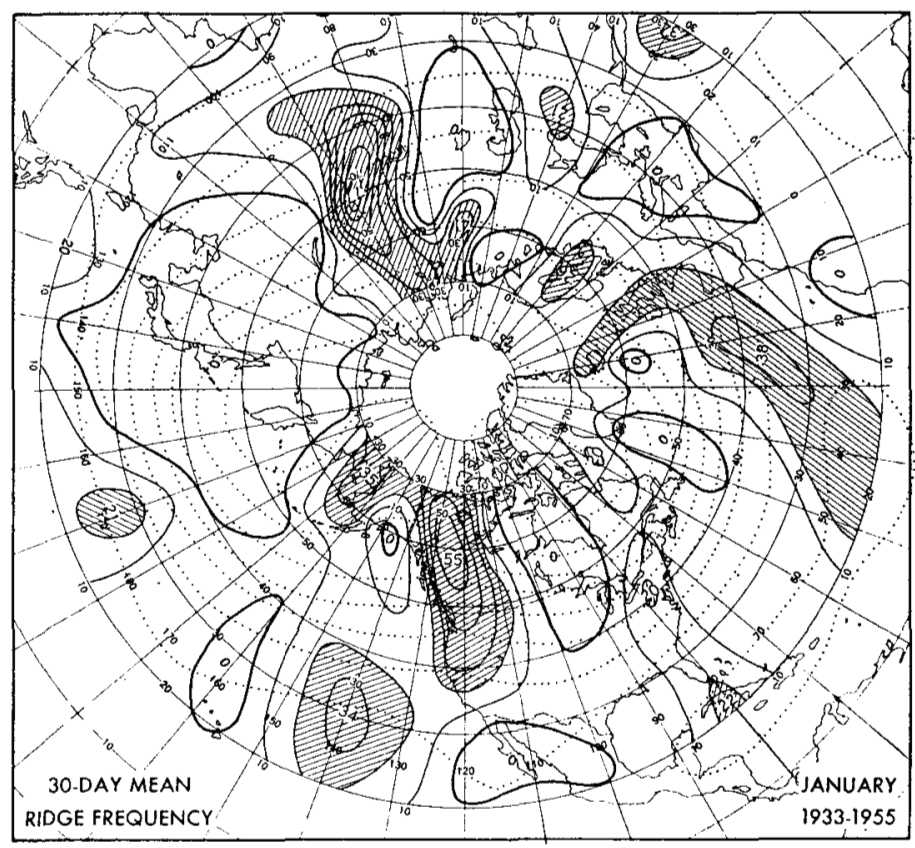

FigURE 4.

FiguRes 1-48.--Percent of time that troughs (ridges) on 5-day and 30-day mean 700-mb. charts were located within $10^{\circ}$ longitude intervals at latitudes from $30^{\circ} \mathrm{N}$. (20 $20^{\circ} \mathrm{N}$. for 30-day charts) to $70^{\circ} \mathrm{N}$. for the month and period of record indicated in the lower right-hand corner of each chart and also in table 1 . The data were adjusted to an equivalent basis with $10^{\circ}$ of longitude at $50^{\circ} \mathrm{N}$. as the unit by use of the coefficients listed in table 2 . The lines of equal frequency are drawn at intervals of 5 percent for 5 -day charts (except 10 percent for frequencies above 20 percent) and at 10-percent intervals on 30-day charts, with the zero line heavier. Areas with frequency greater than 15 percent (20 percent for 30 -day charts) are shaded. Centers of maximum frequency are labeled in large numerals; centers of minimum frequency in small numerals. The unlabeled dotted lines are the normal 700-mb. contours [17] for the month, drawn at intervals of $200 \mathrm{ft}$. 


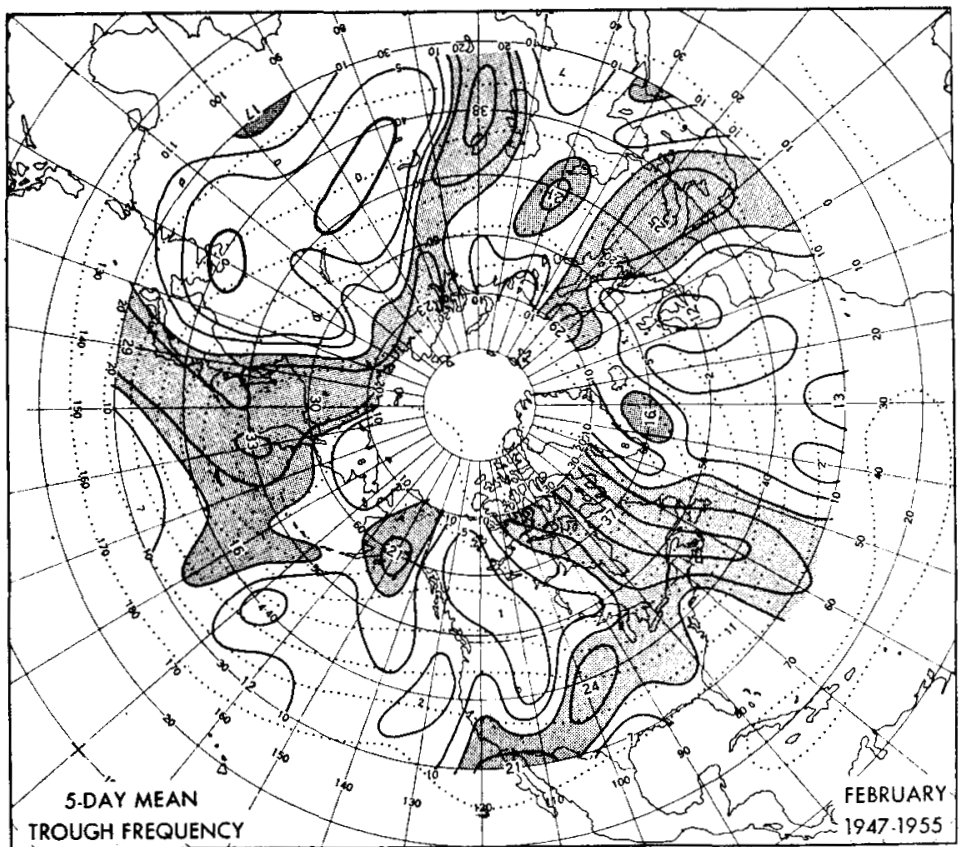

Frgure 5.

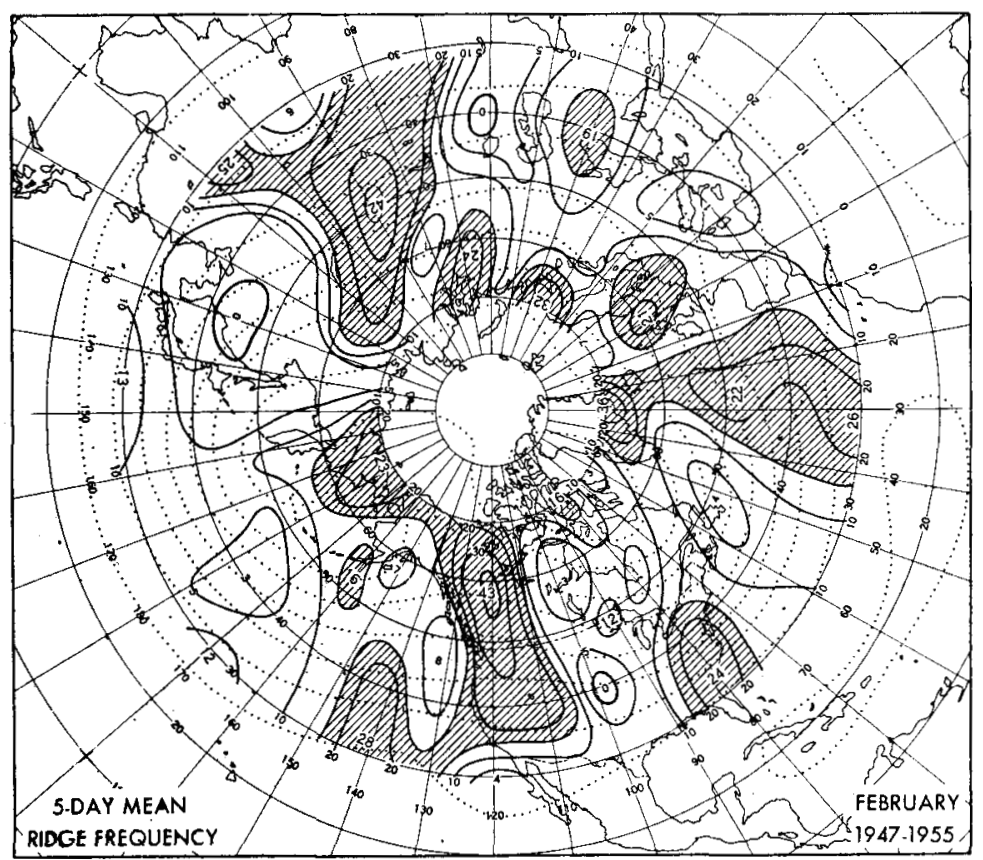

Figure 7.

and mid-Pacific. On the other hand, trough frequency increases markedly from April to May over the Pacific Northwest and in eastern Siberia.

The reversal from summer to winter patterns may also take place in an abrupt fashion at different times. Marked increases in trough frequency are evident from August to September over Japan, Alaska, the Gulf of Alaska, and the Mississippi Valley. Similar changes occur a month later (from September to October) in the central Mediterranean and Egypt. The opposite type of transition, from high to low trough frequency, is manifest over the northern Plateau region from August to September and

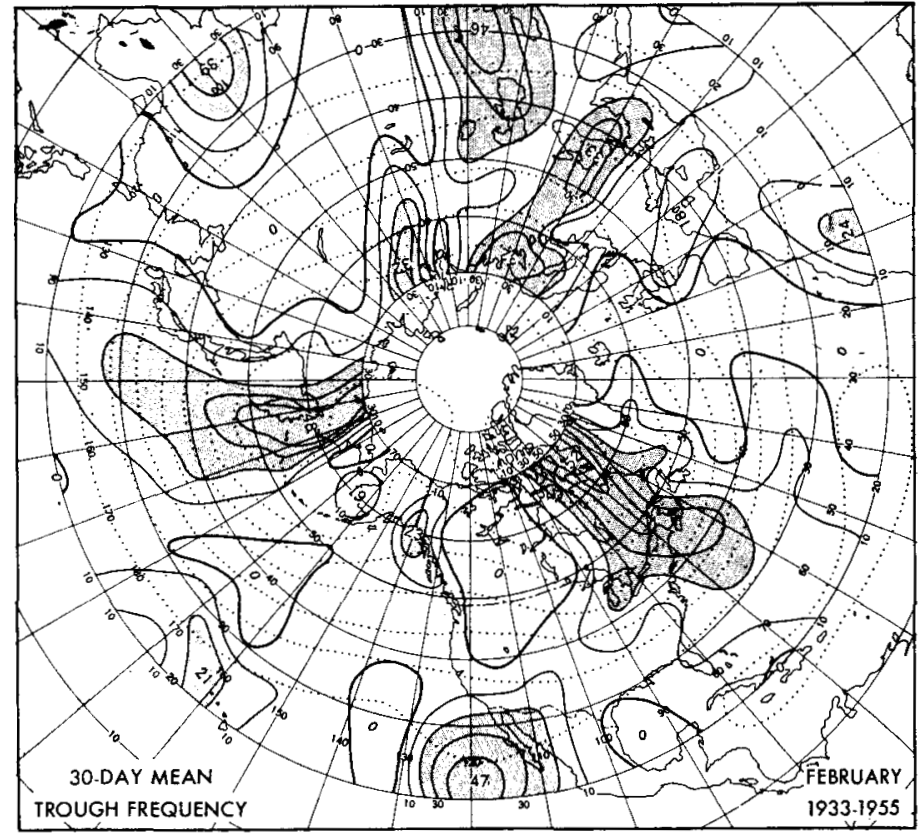

Figure 6.

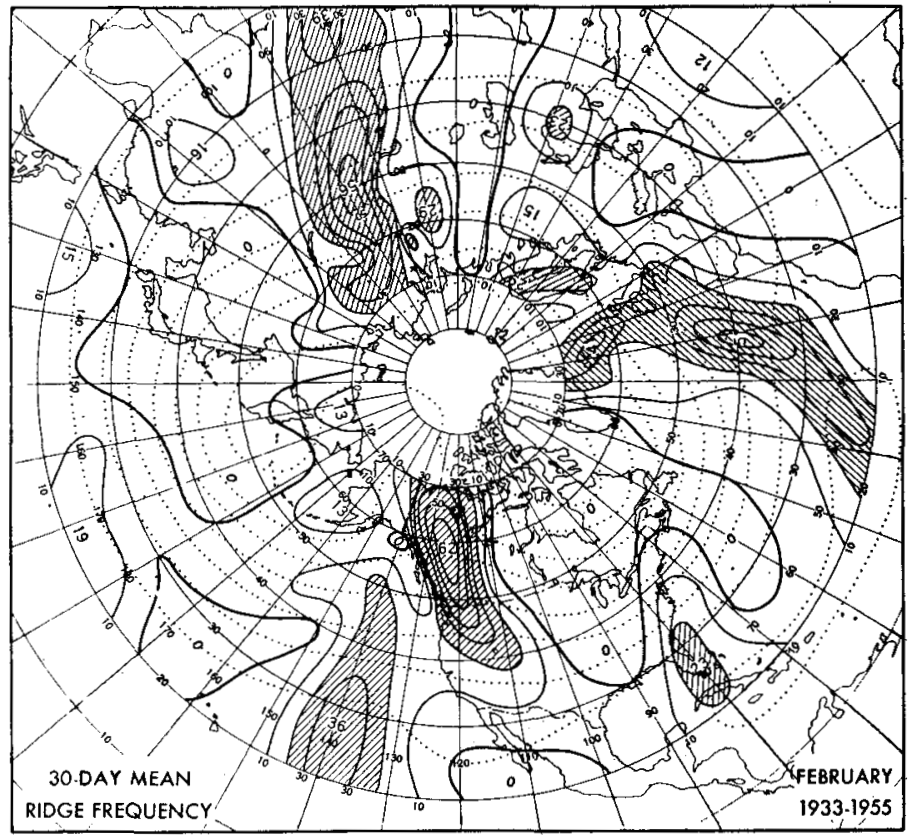

Figure 8.

over Korea and Manchuria from September to October.

In some regions troughs are infrequent during practically all of the year. The most striking example is the area of the Canadian Divide, where frequencies reach as low as 0 or 1 percent on 23 out of the 24 charts for troughs. Other areas of rather persistent low trough frequency are the Texas gulf coast, the Greenland Plateau, and eastcentral portions of the Atlantic and Pacific.

In the central portion of the United States the frequency of 5-day mean troughs is somewhat greater than the frequency of 30-day mean troughs during the first 5 months of the year. This may reflect the well-known tendency 


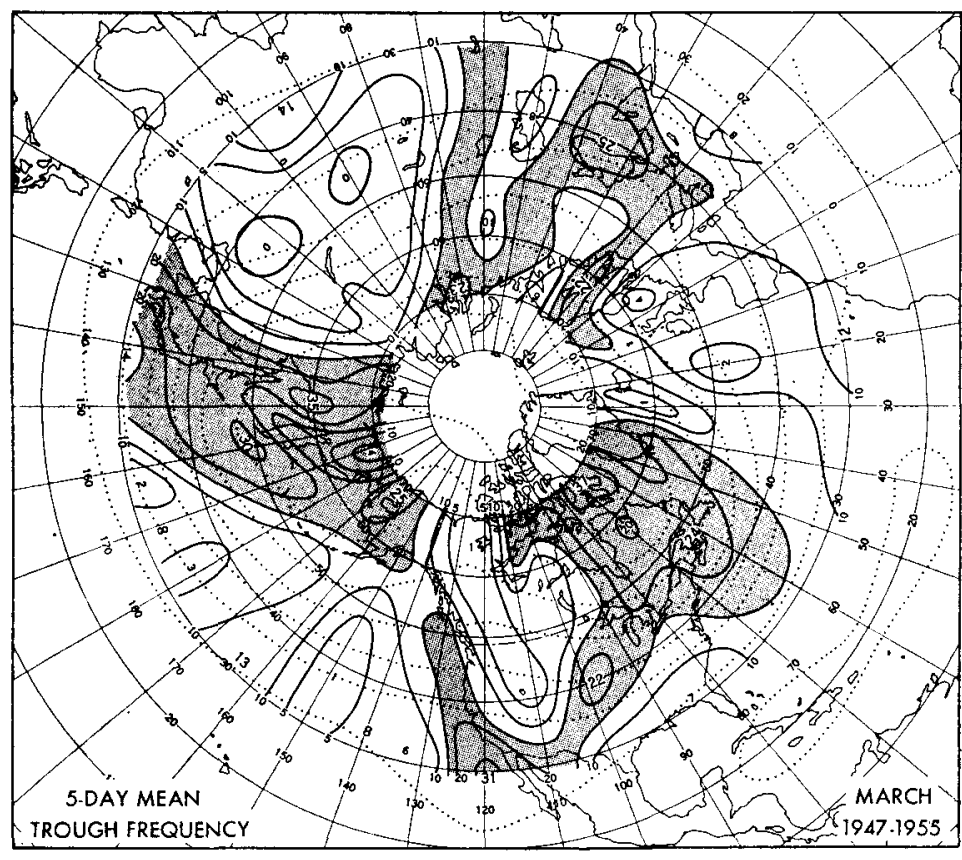

Figure 9.

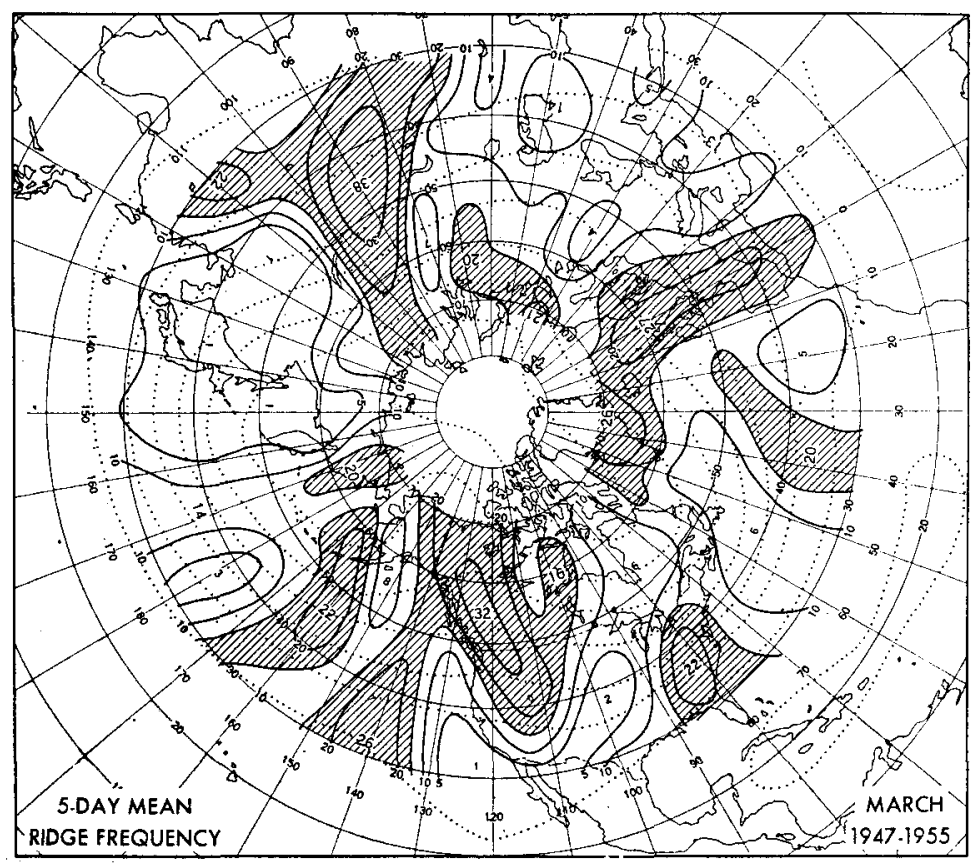

FIGURE 11.

for troughs on shorter period mean maps to develop in the lee of the Rocky Mountains and then to move rapidly eastward and deepen near the east coast $[8,12]$.

Another interesting feature is the tendency for a weak axis of maximum trough frequency to be located along or off the entire west coast of North America. This tendency is evident not only during the summer months, when a trough is present in the normal contours, but also during most other months of the year, when the normal contours indicate a ridge or straight flow. The orientation of the maximum frequency axis is generally parallel to the coastline and apparently reflects the fact that many

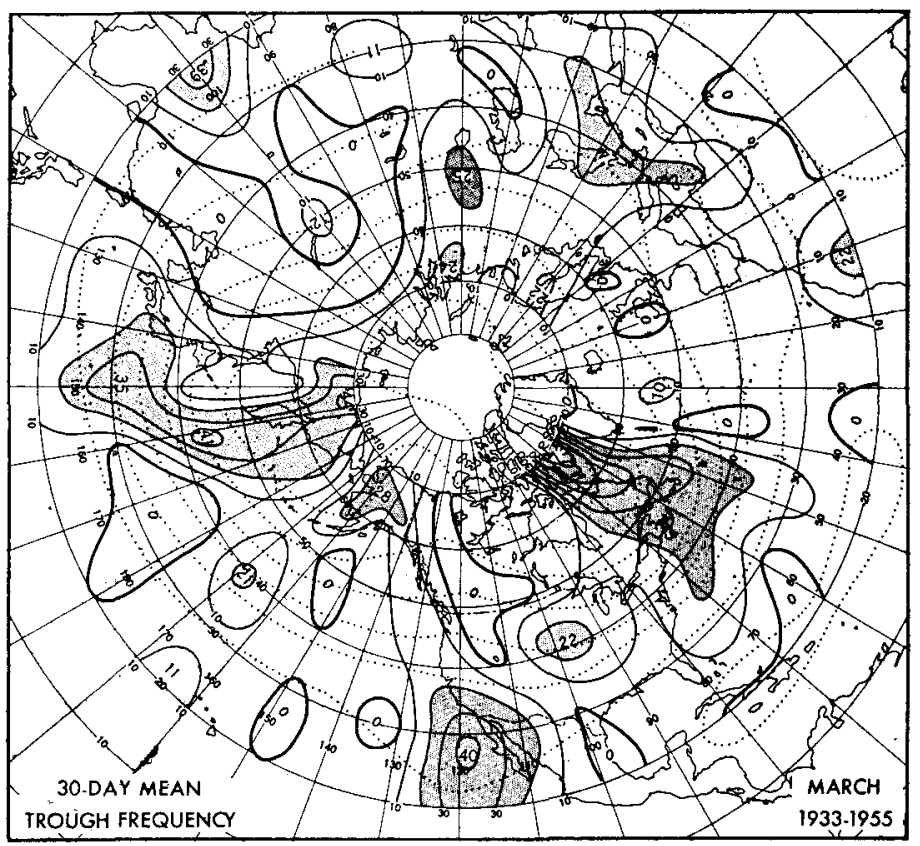

Figure 10.

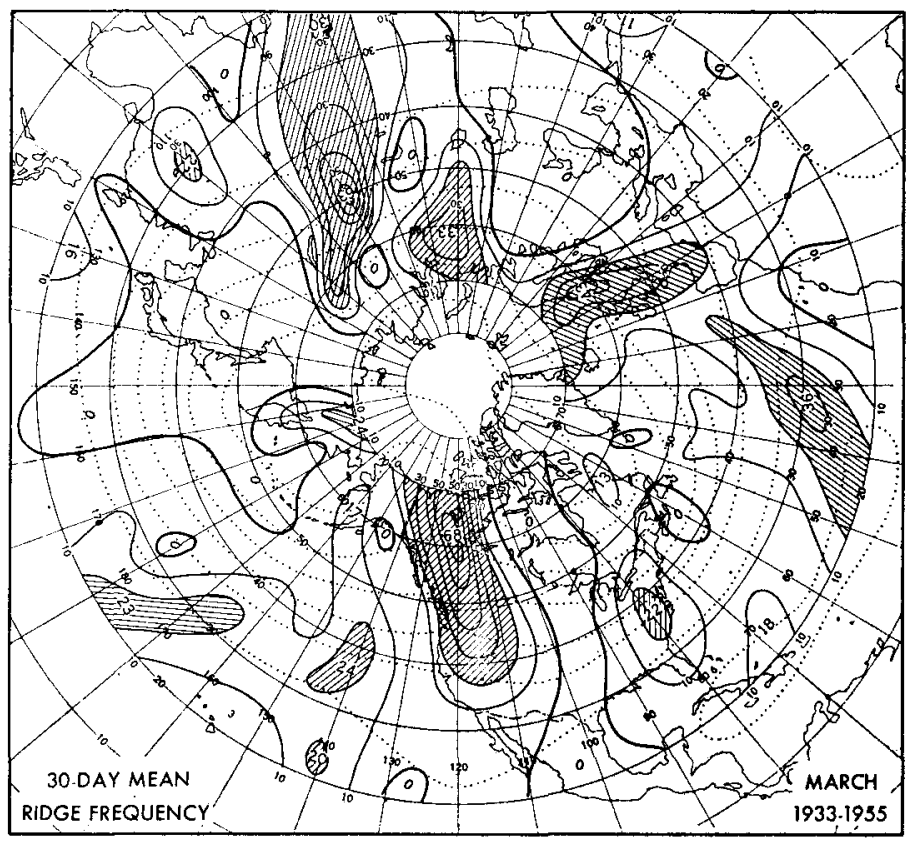

Figure 12. troughs in this area are favored by topographical features to assume a negative horizontal tilt; i. e., from northwest to southeast.

\section{RIDGES}

The frequency distributions of ridges are to a large extent inverse to those of troughs in corresponding months. Ridges are scarce most of the year in regions where troughs congregate, such as eastern Canada, the western Atlantic, Lower California, the eastern Mediterranean, and the west coast of Africa. A similar condition prevails during the colder months of the year along the east coast of Asia, in the central United States, and near the Hawaiian 


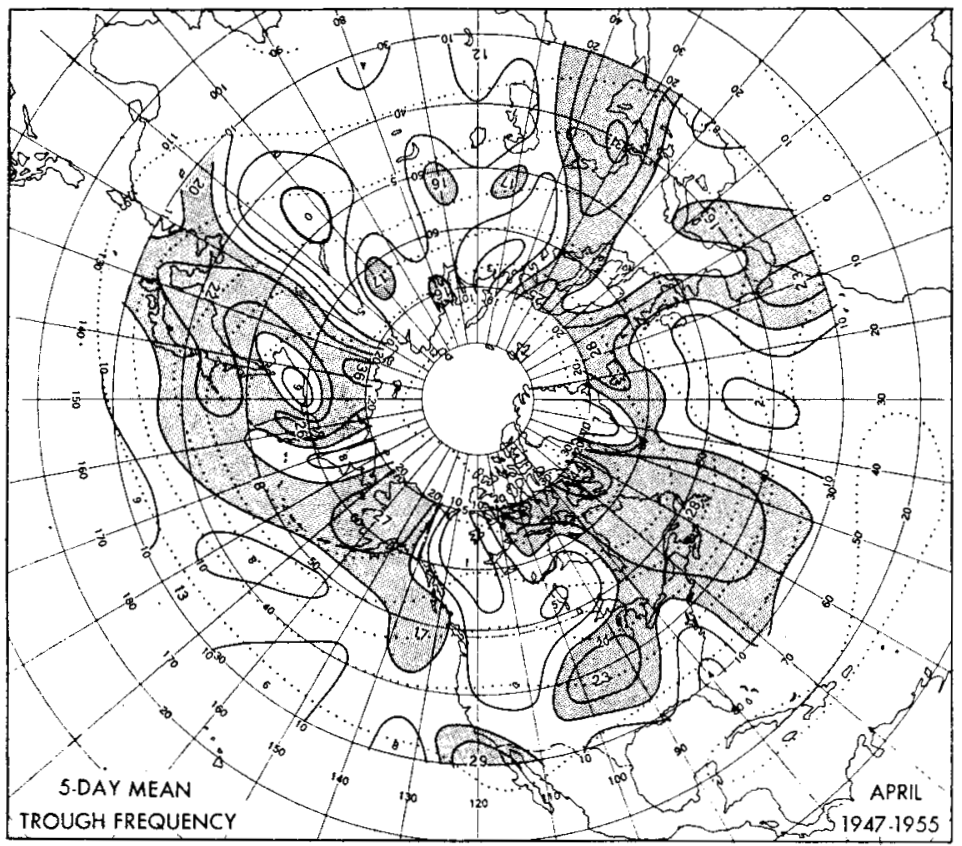

FIGURE 13.

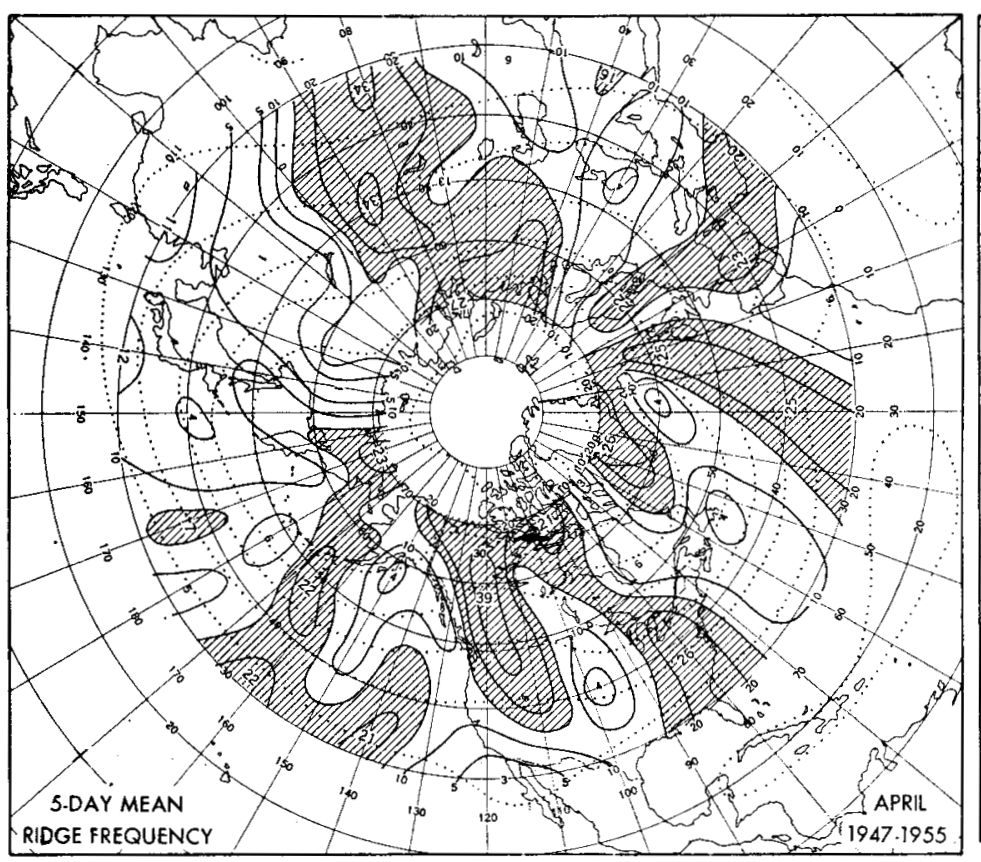

Figure 15.

Islands, and during the warmer months in the vicinity of the Bering Sea and the Black Sea.

On the other hand, ridges are abundant in sections with few troughs. The most conspicuous example is western Canada, where a strong concentration of ridges is found near the ridge in the normal contours over the Continental Divide during every month of the year. This preponderance of ridges west of the Rockies is generally attributed to divergence which results as westerly flow is forced to ascend the western slopes of the mountains (cf., Bolin [3] and Charney and Eliassen

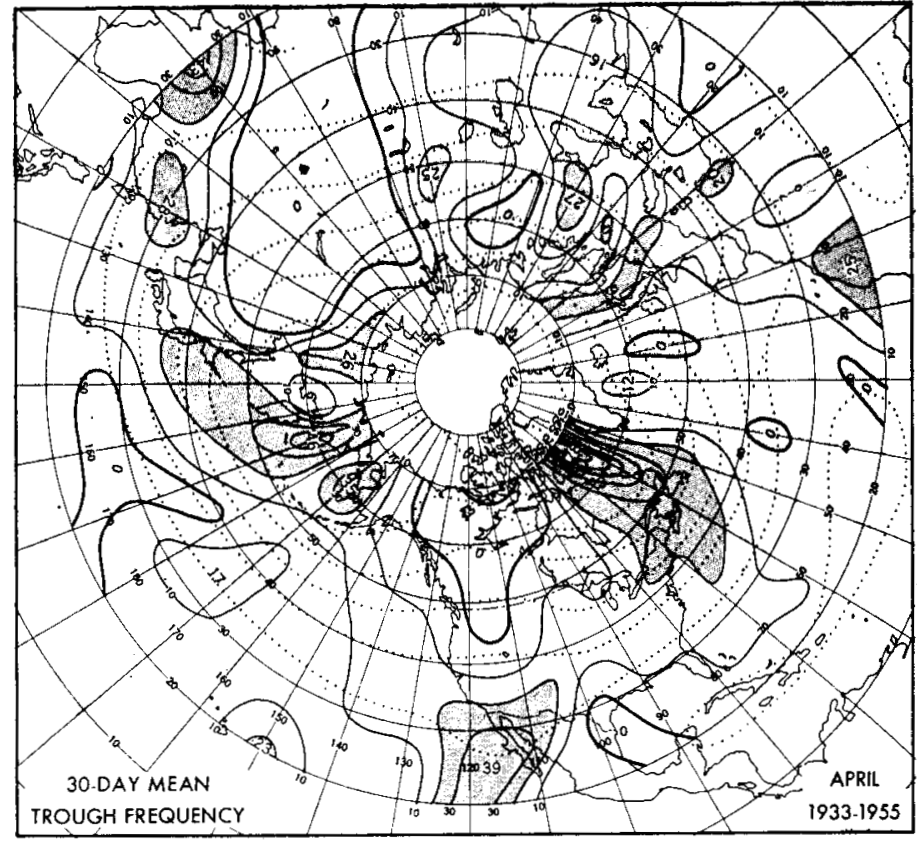

FigdRe 14.

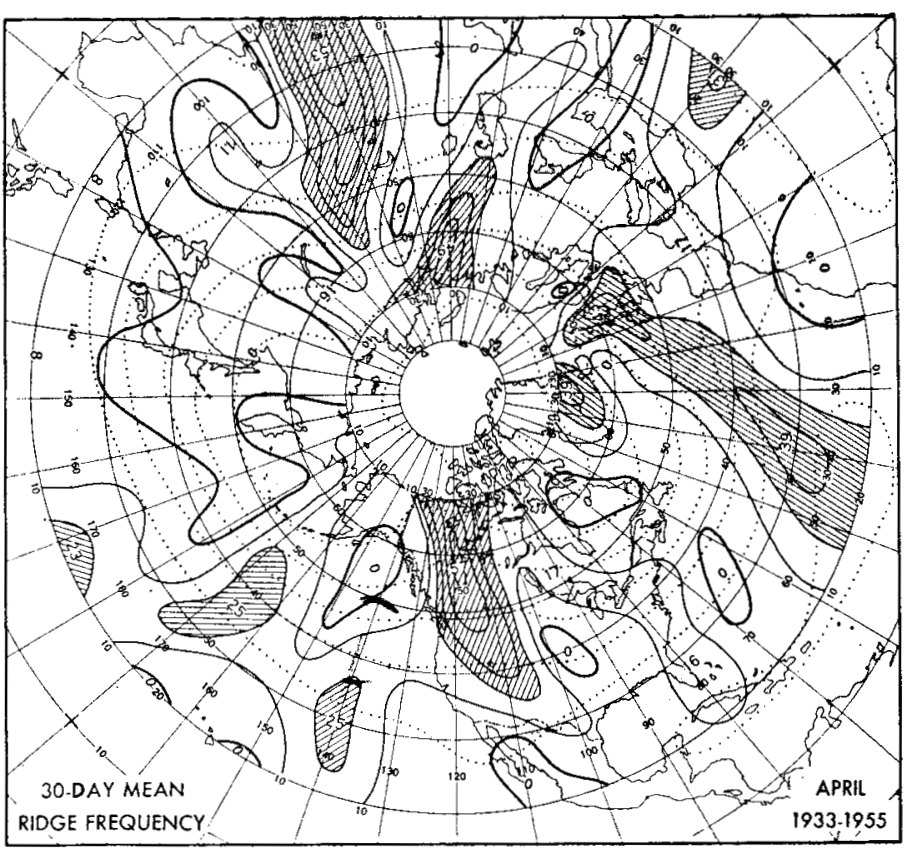

FigUre 16.

[5]). The fact that the maximum frequency maintains over Canada throughout the year, while its southward extension weakens and shifts eastward in summer in conjunction with the seasonal decrease in westerlies over the western United States and southwestern Canada, lends support to this theory. Other areas with many ridges and few troughs during much of the year are the eastern portions of the oceans, in the vicinity of the semipermanent Azores and eastern Pacific Highs, central Asia just west of Lake Baikal, and Greenland.

The seasonal variation of ridge frequency also tends 


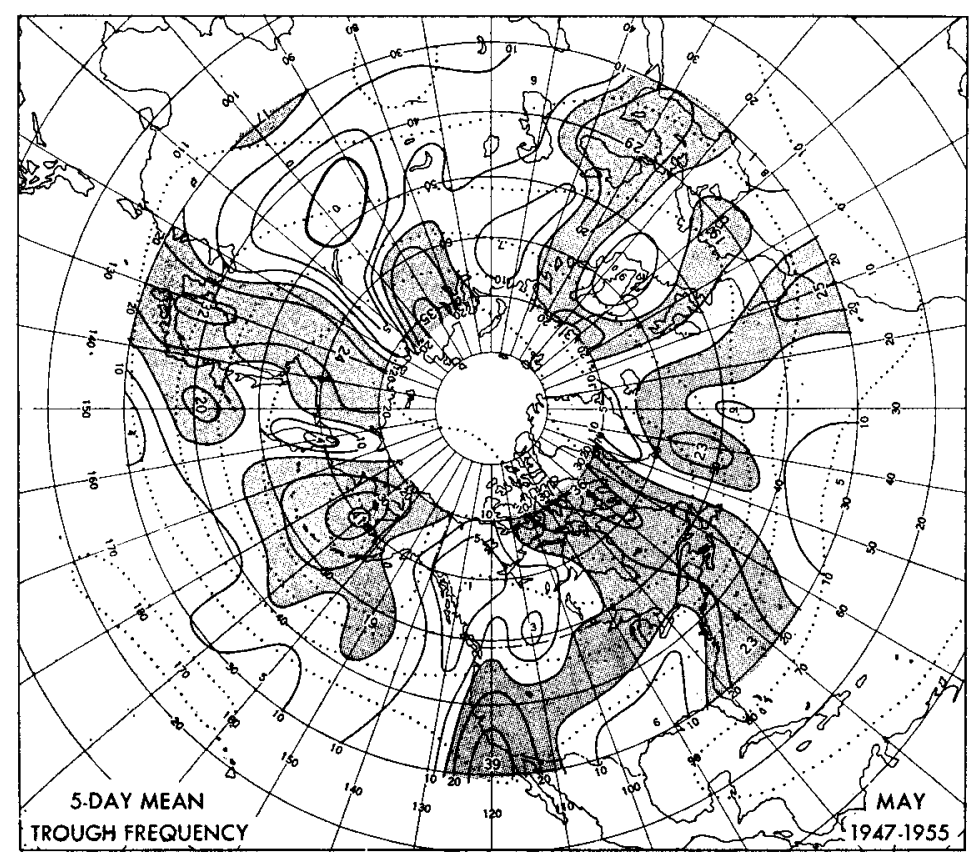

Figdre 17.

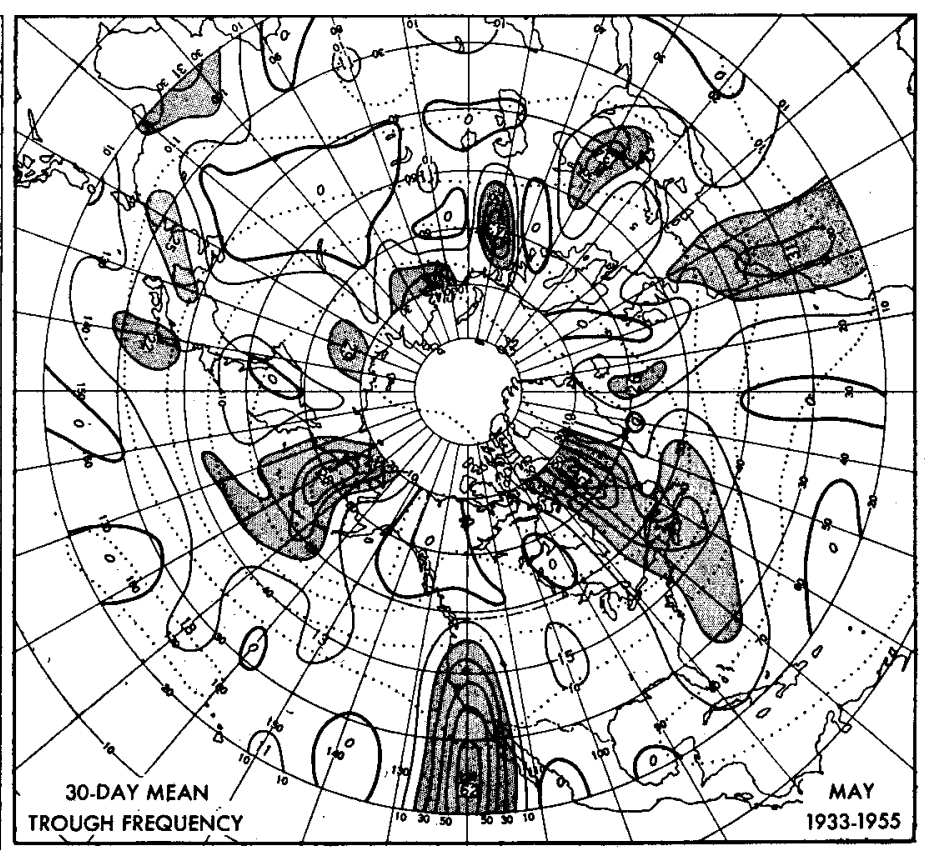

FiguRE 18.

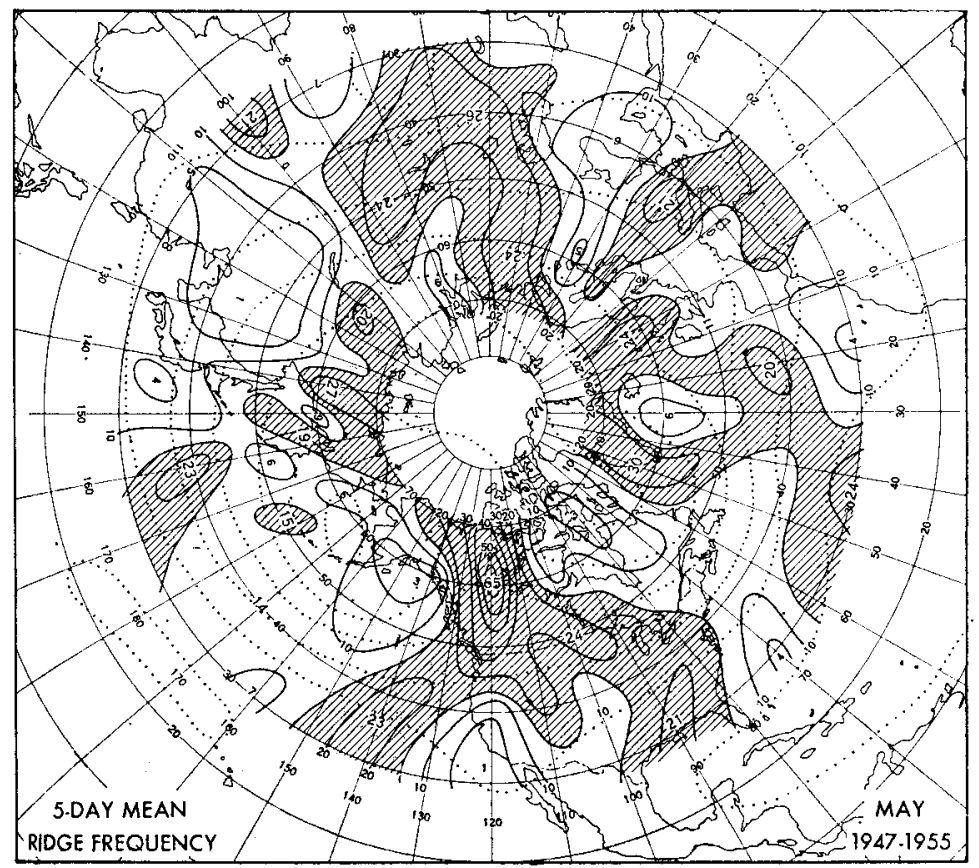

Figure 19.

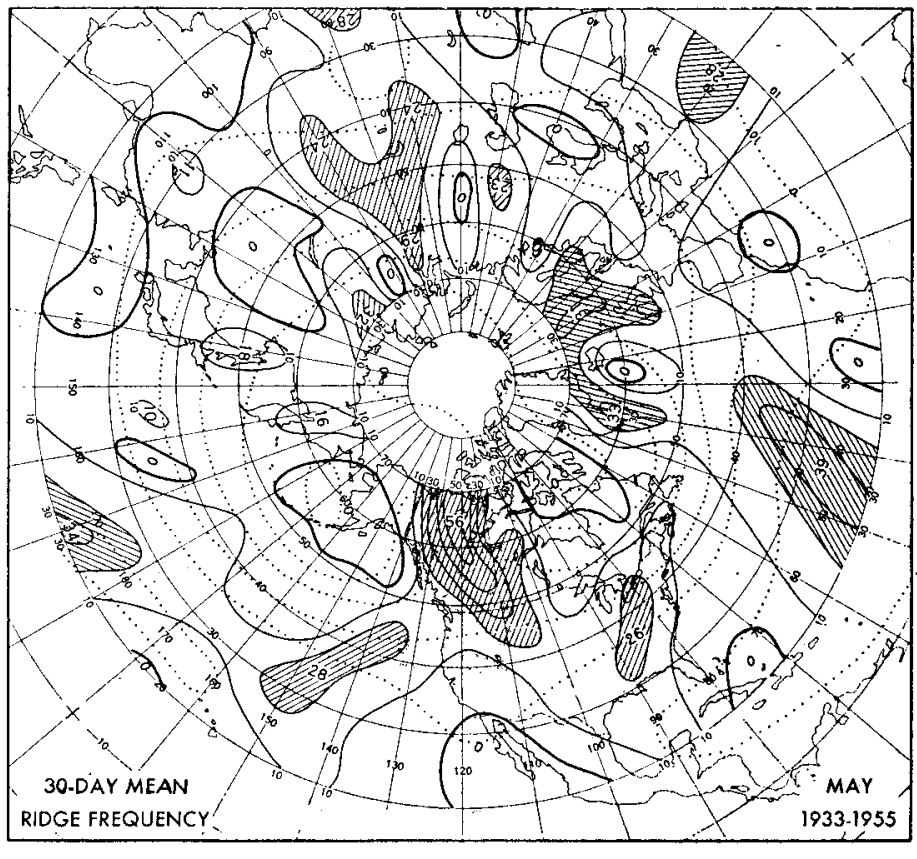

Figure 20. to be the reverse of that of troughs. In areas where troughs are frequent during all but the summer months, ridges are frequent only during summer. This behavior can be noted in the central United States, in Japan and the Sea of Okhotsk, in Alaska and the Gulf of Alaska, and in the Mediterranean. An opposite type of seasonal variation, in which ridges are more frequent (and troughs less frequent) in winter than summer occurs in the Pacific Northwest region of the United States, over the British Isles, and in the Bering Sea, with much of the transition occurring from May to June and from September to October.

The dominance of anticyclonic circulation over the central United States during summer has been attributed to surface heating over the continent by Reed [14] and to the downstream consequence of the thermally fixed west coast trough by Wexler [18]. The onset of the summertype pattern is manifested by a sharp increase in ridge frequency in the Great Plains of the United States from June to July (figs. $23,24,27,28$ ), corresponding to a 


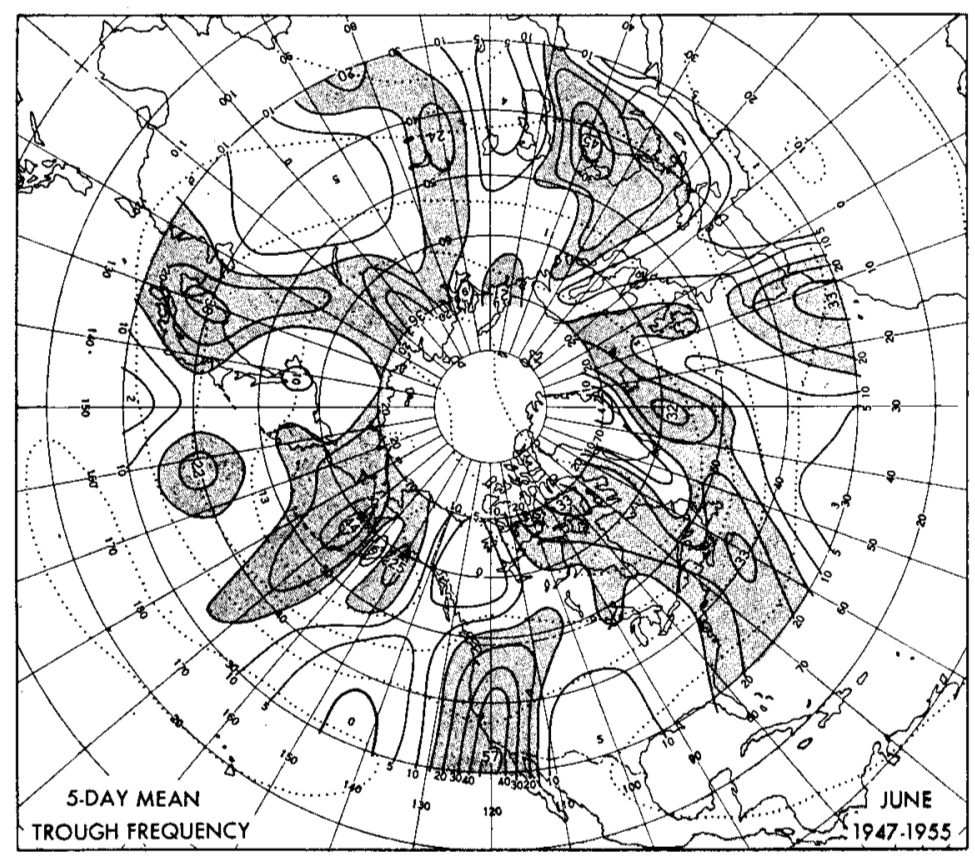

FigURe 21.

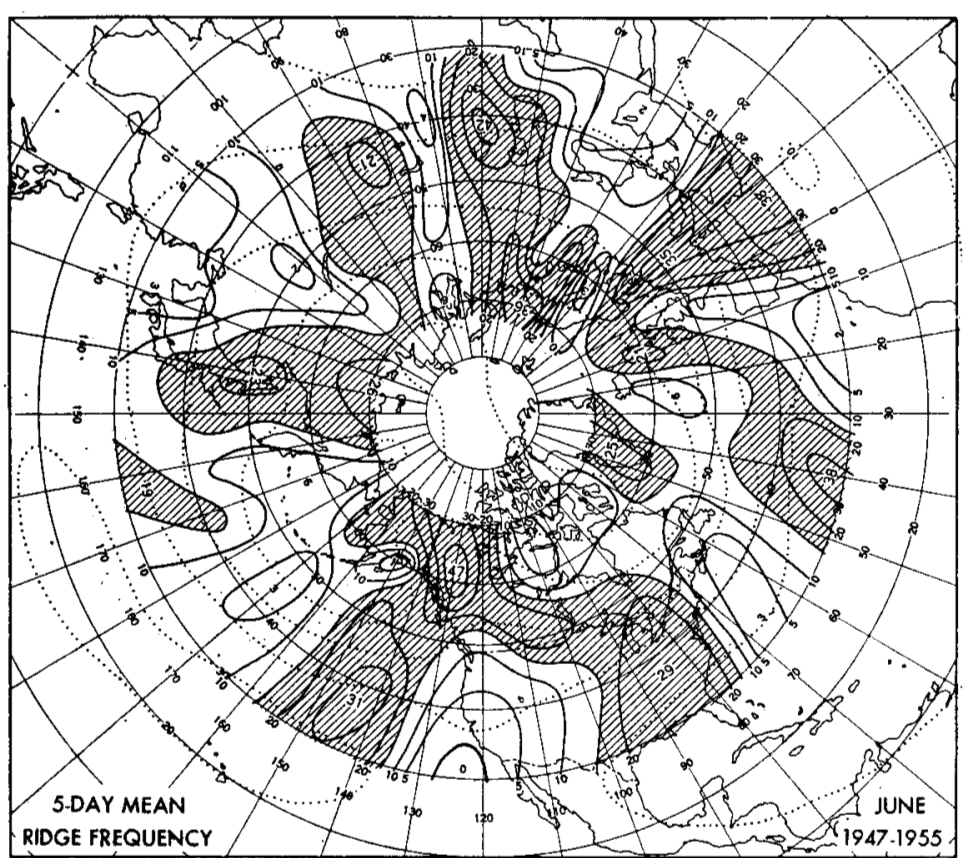

Figure 23.

well-known singularity in Arizona precipitation [4, 14]. This type of winter-summer reversal takes place a month earlier (from May to June) in Japan and Alaska, where surface heating is probably responsible.

In some areas both ridges and troughs are fairly frequent during certain months of the year; e. g., in parts of the Aleutians, the Icelandic region, and the east coast of North America. These are important centers of action in which the variability of $700-\mathrm{mb}$. height is relatively large. On the contrary, both ridges and troughs are infrequent around western Hudson Bay (in winter),

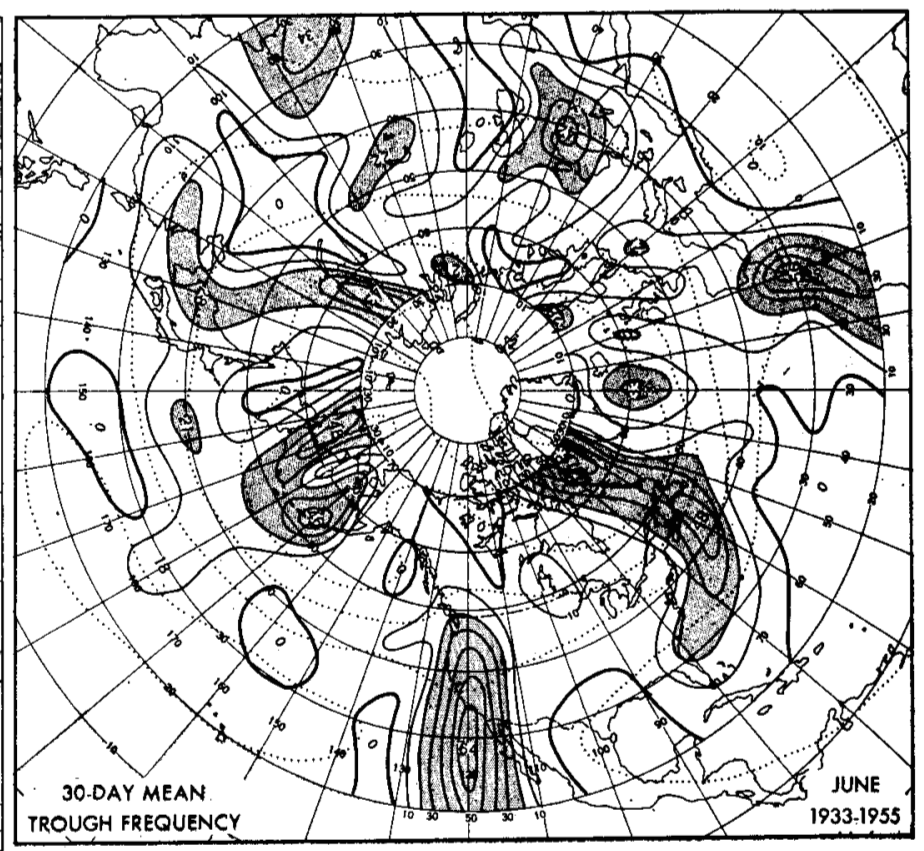

Figure 22.

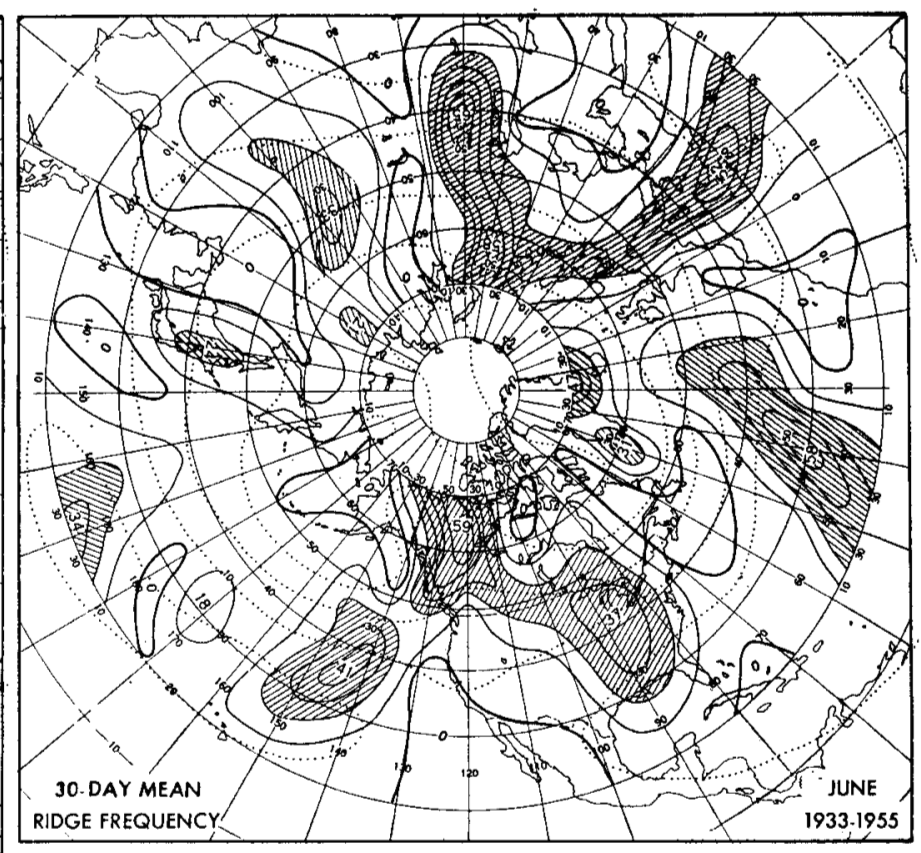

FigURE 24.

between Lake Baikal and the Sea of Japan (during the cold months), and in the western Gulf of Mexico (except fall). These are areas where relatively straight flow and small height variability normally prevail at the $700-\mathrm{mb}$. level. It would be especially difficult to anticipate the location of such regions from the normal $700-\mathrm{mb}$. contours alone.

\section{ACKNOWLEDGMENTS}

The authors wish to thank Robert M. Ferry, James F. Andrews, William Drewes, and Mrs. Mildred Matthews 


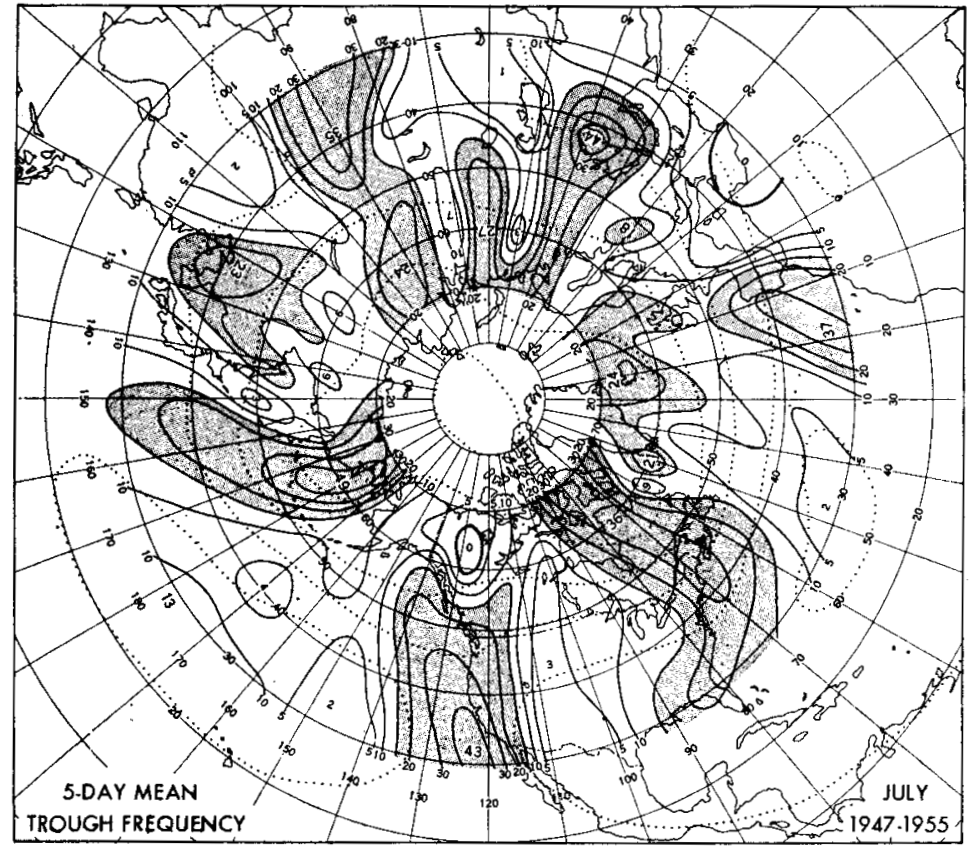

Figure 25.

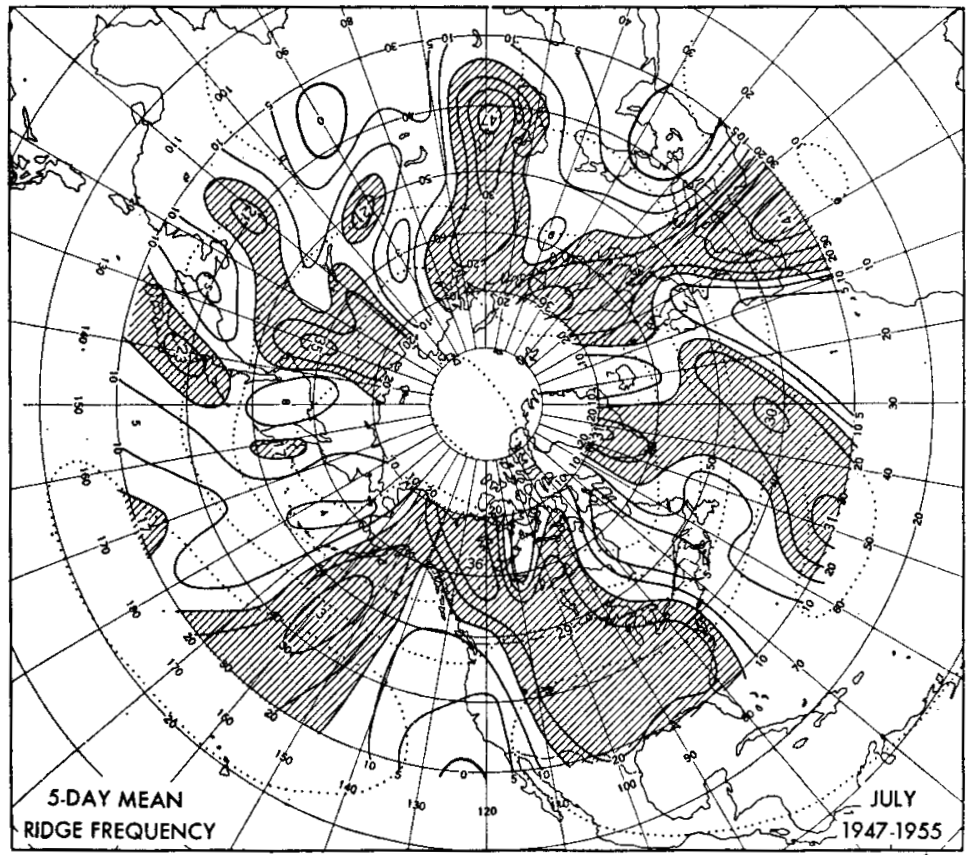

FIgURe 27.

for their valuable help in compiling and analyzing the data on trough-ridge frequency.

\section{REFERENCES}

1. J. M. Austin and Collaborators, "Aspects of Intensification and Motion of Wintertime $500 \mathrm{mb}$. Patterns," Bulletin of the American Meteorological Society, vol. 34, No. 9, Nov. 1953, pp. 383-392.

2. E. M. Ballenzweig, A Practical Equal-Area Grid, unpublished manuscript, Extended Forecast Section, U. S. Weather Bureau, 1958.

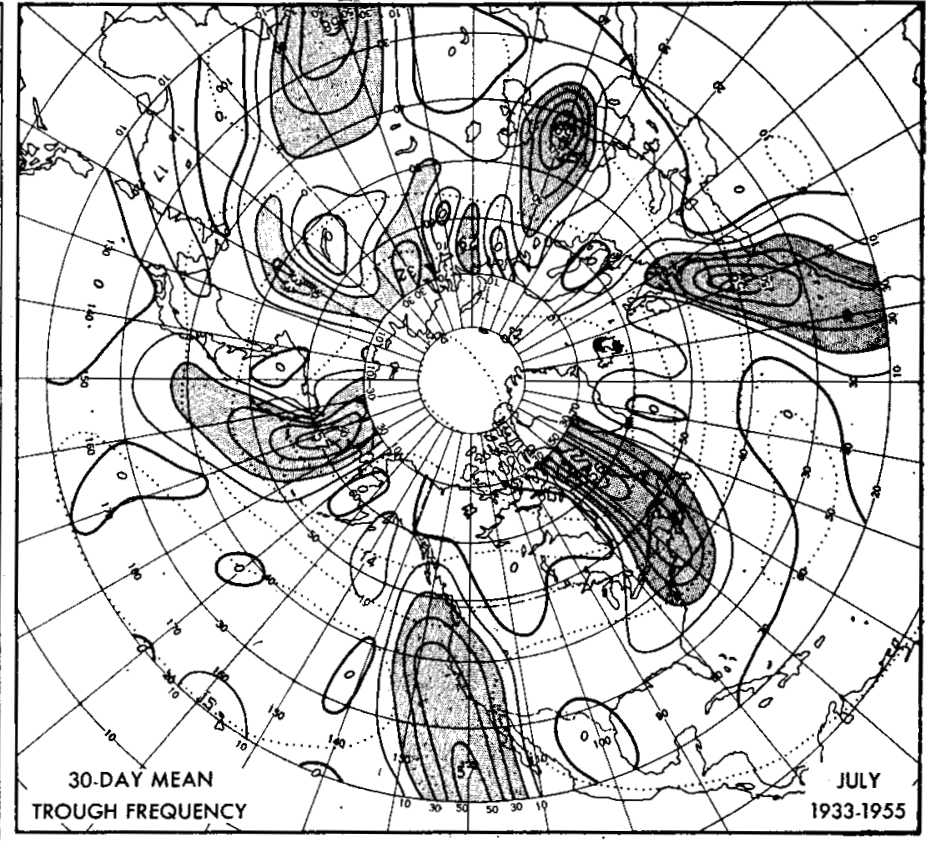

Figure 26.

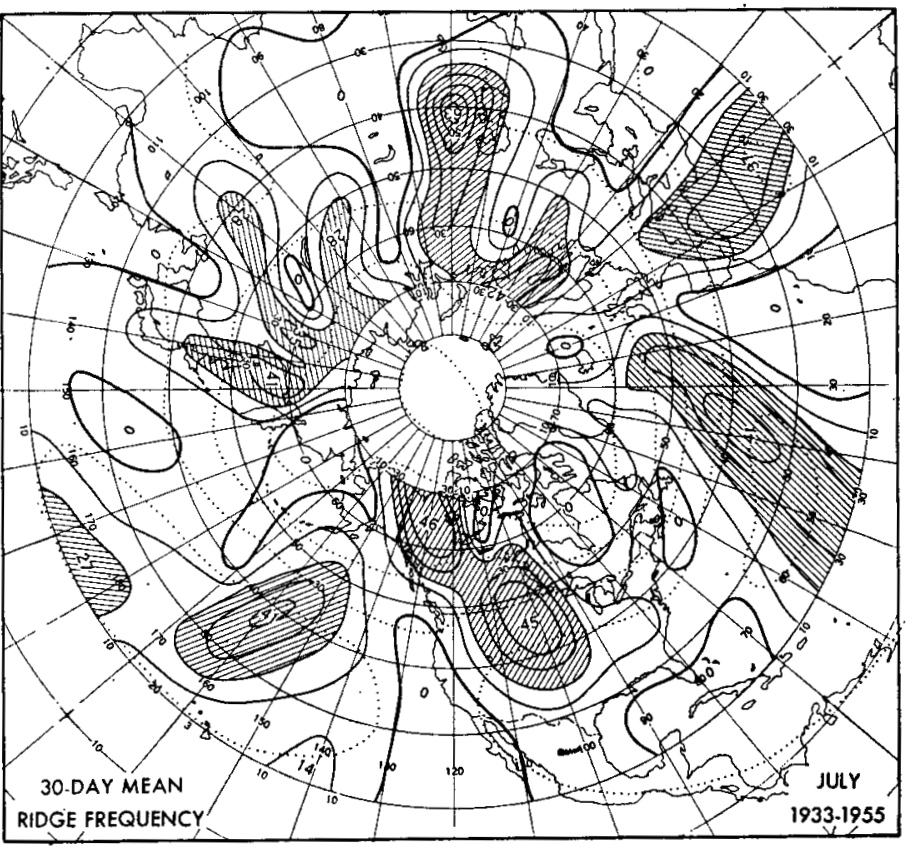

Figure 28.

3. B. Bolin, "On the Influence of the Earth's Orography on the General Character of the Westerlies," Tellus, vol. 2, No. 3 Aug. 1950, pp. 184-195.

4. R. A. Bryson, and W. P. Lowry, "Synoptic Climatology of the Arizona Summer Precipitation Singularity," Bulletin of the American Meteorological Society, vol. 36, No. 7, Sept. 1955, pp. 329-339.

5. J. G. Charney and A. Eliassen, "A Numerical Method for Predictine the Perturbations of the Middle Latitude Westerlies," Tellus, vol. 1, No. 2, May 1949, pp. 38-54.

6. W. Dammann, "Die Verbreitung der Höhentröge in der 500-mb. Fläche und ihr Einfluss__auf_das_Klima der gemässigten 


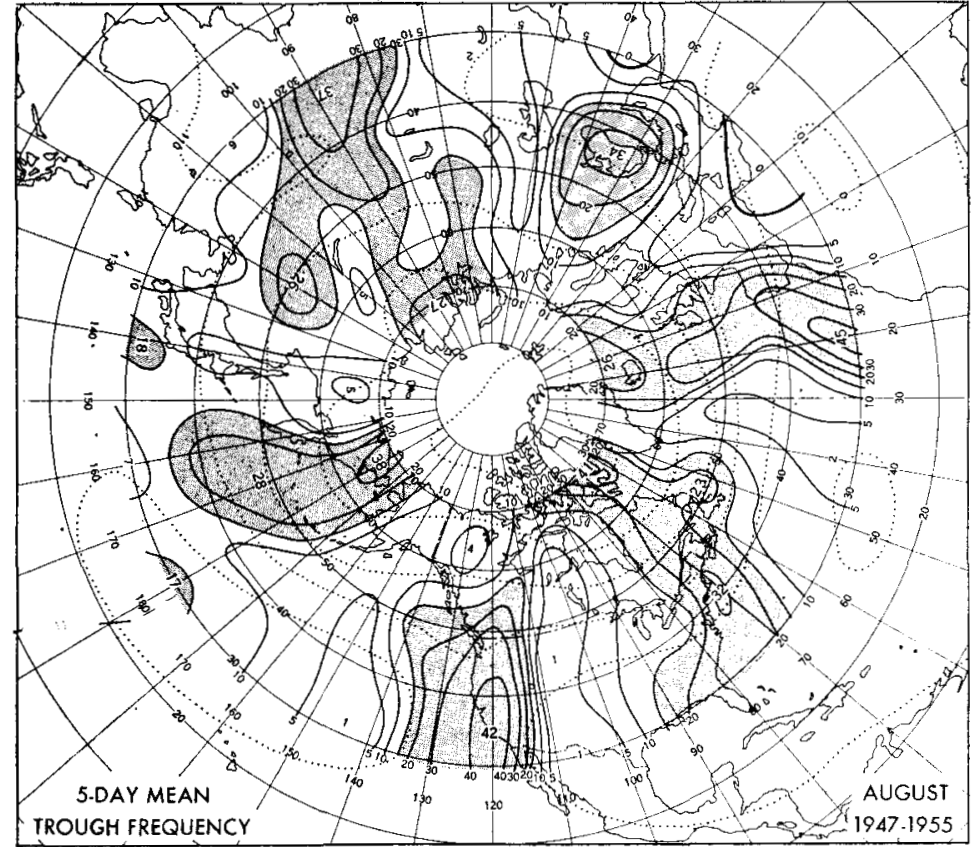

FIGURE 29.

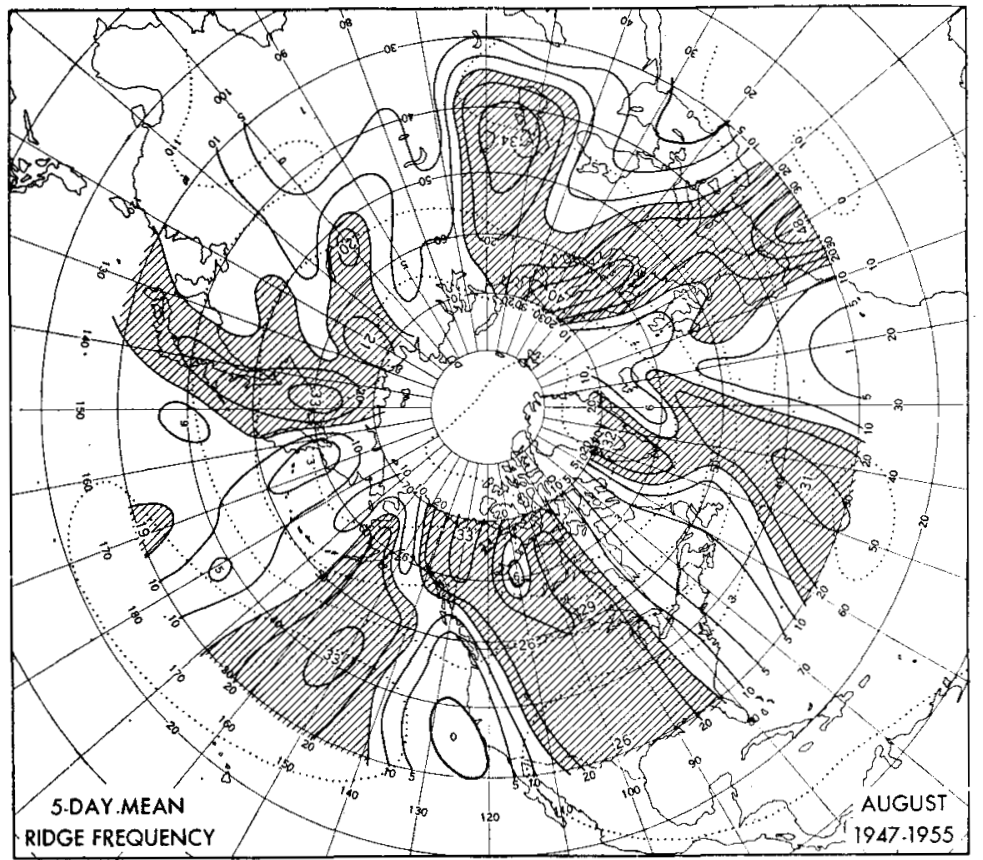

Figure 31.

Breiten," Berichte des Deutschen Wetterdienstes in der U.S. Zone, No. 42, Knoch-Heft, 1952, Bad Kissingen, pp. 195-199.

7. O. Essenwanger, "Statistische Untersuchungen über die Zirkulation der Westdrift in $55^{\circ}$ Breite," Berichte des Deutschen Wetterdienstes, No. 7, 1953, $22 \mathrm{pp}$.

8. W. H. Klein, "Some Empirical Characteristics of Long Waves on Monthly Mean Charts," Monthly Weather Review, vol. 80, No. 11 , Nov, 1952 , pp. 203-219.

9. W. H. Klein, "The Weather and Circulation of January 1955A Month With a Mean Wave of Record Length," Monthly Weather Review, vol. 83, No. 1, Jan. 1955, pp. 14-22.

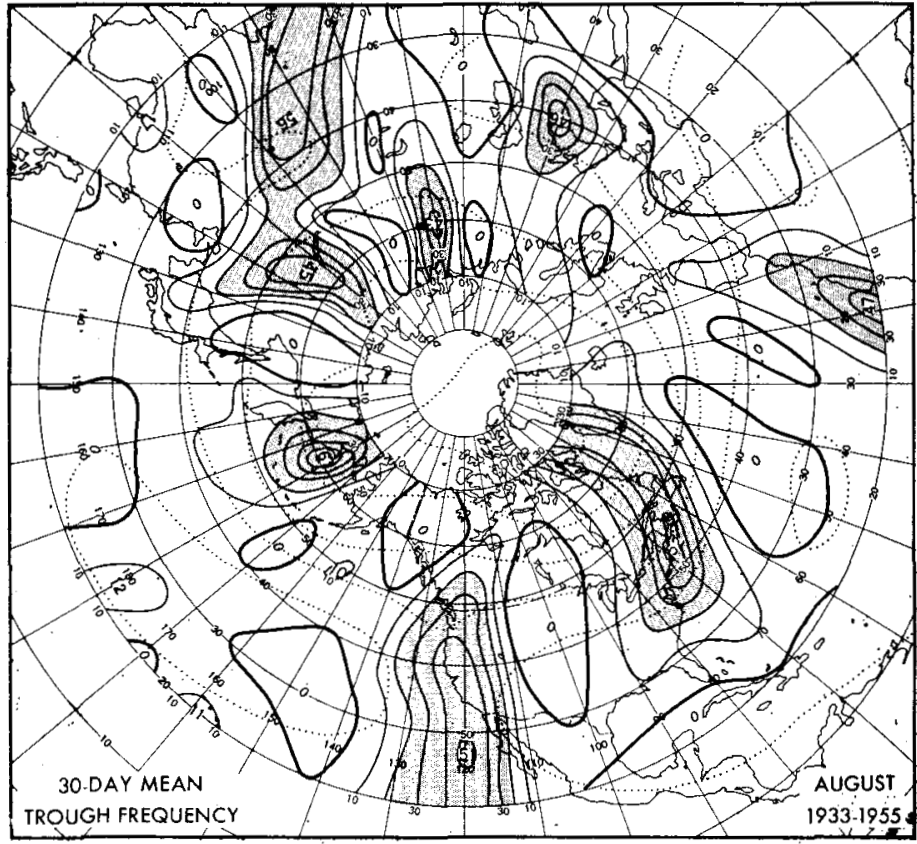

FigURE_30.

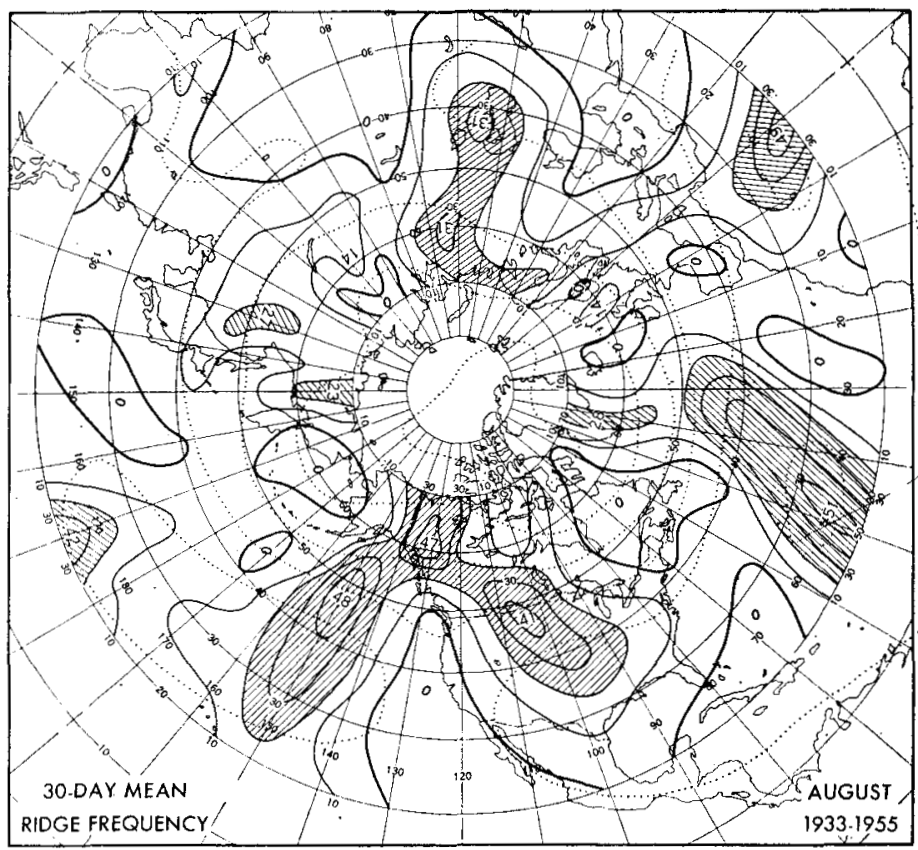

FigURe 32

10. W. H. Klein, "Principal Tracks and Mean Frequencies of Cyclones and Anticyclones in the Northern Hemisphere," Research Paper No. 40, U. S. Weather Bureau, Washington, D. C., 1957, 60 pp.

11. J. E. Miller, "Studies of Large Scale Vertical Motions of the Atmosphere," New York University Meteorological Papers, vol. 1, No. 1, July 1948, 49 pp.

12. J. Namias, "Thirty-Day Forecasting: A Review of a Ten-Year Experiment," Meteorological Monographs, vol. 2, No. 6, American Meteorological Society, Boston, July 1953, 83 pp. 13. J. Namias and P. F. Clapp, "Studies of the Motion and De- 


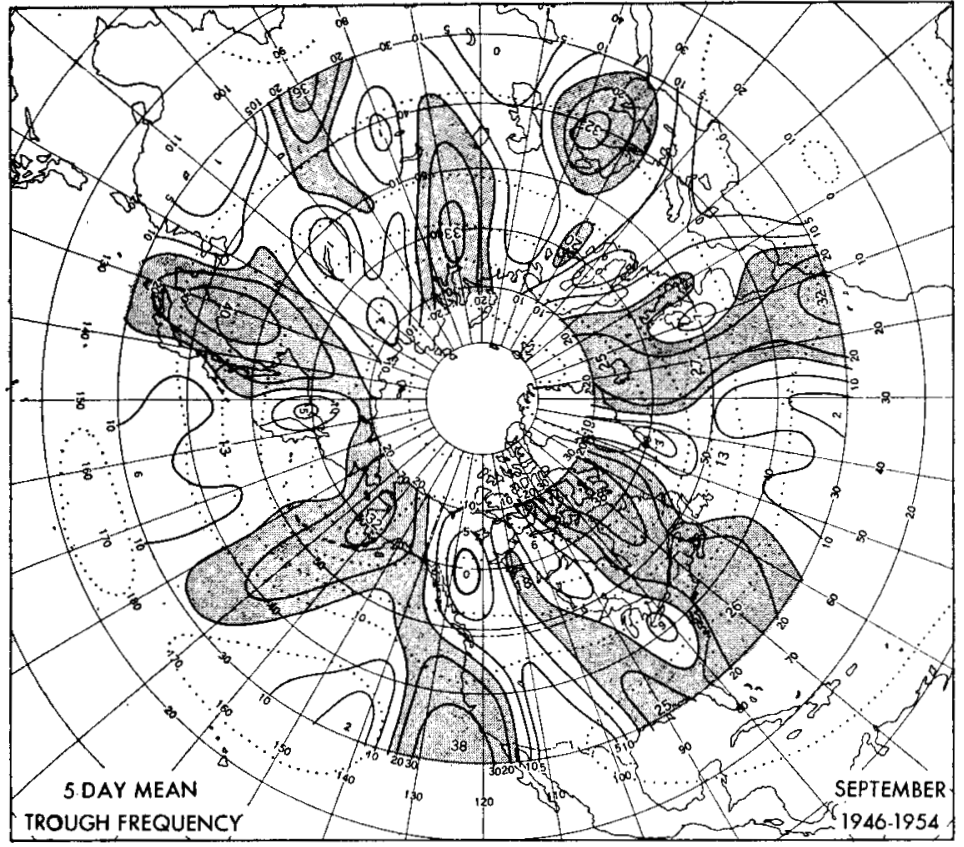

Figure 33.

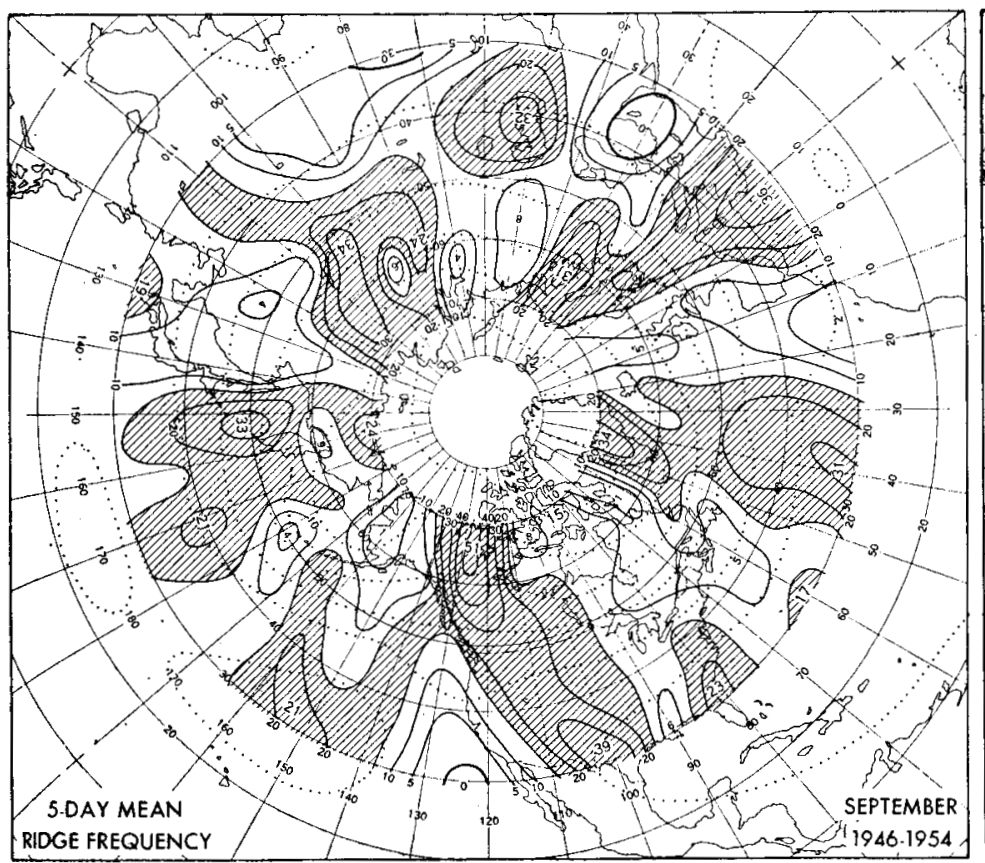

Figure 35 .

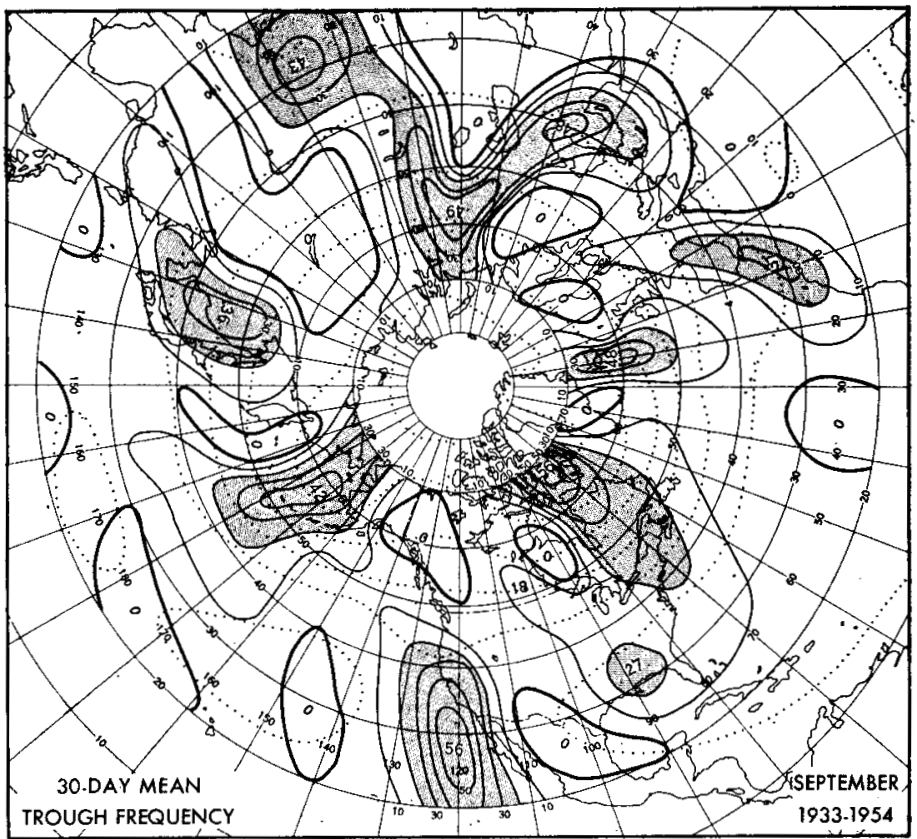

Figure 34.

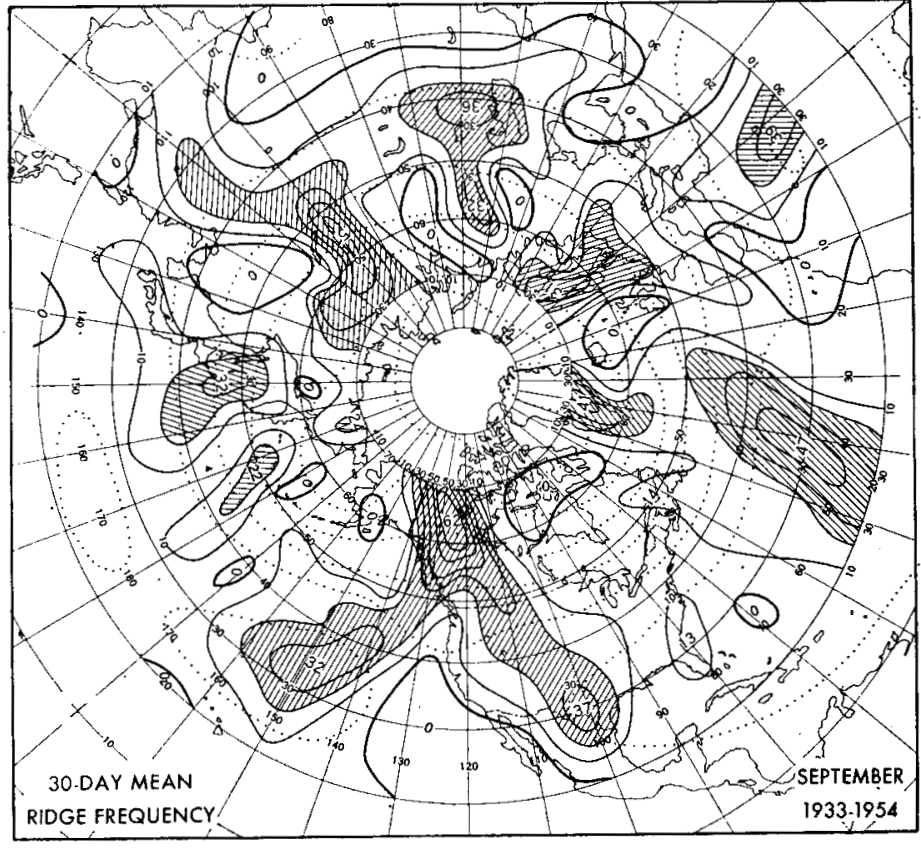

FIGURE 36. velopment of Long Waves in the Westerlies," Journal of Meteorology, vol. 1, Nos. 3 and 4, Dec. 1944, pp. 57-77.

14. T. R. Reed, "The North American High-Level Anticyclone," Monthly Weather Review, vol. 61, No. 11, Nov. 1933, pp. 321-325.

15. J. Smagorinsky, "The Dynamical Influence of Large-Scale Heat Sources and Sinks on the Quasi-Stationary Mean Motions of the Atmosphere," Quarterly Journal of the Royal Meteorological Society, vol. 79, No. 341, July 1953, pp. 342366.
16. R. C. Sutcliffe, "Mean Upper Contour Patterns of the Northern Hemisphere-The Thermal-Synoptic View-point," Quarterly Journal of the Royal Meteorological Society, vol. 77, No. 333, July 1951, pp. 435-440.

17. U. S. Weather Bureau, "Normal Weather Charts for the Northern Hemisphere," Technical Paper No. 21, Washington, D. C., Oct. 1952, $74 \mathrm{pp}$.

18. H. Wexler, "Some Aspects of Dynamic Anticyclogenesis," The University of Chicago, Institute of Meteorology, Miscellaneous Reports No. 8, Jan. 1943, 28 pp. 


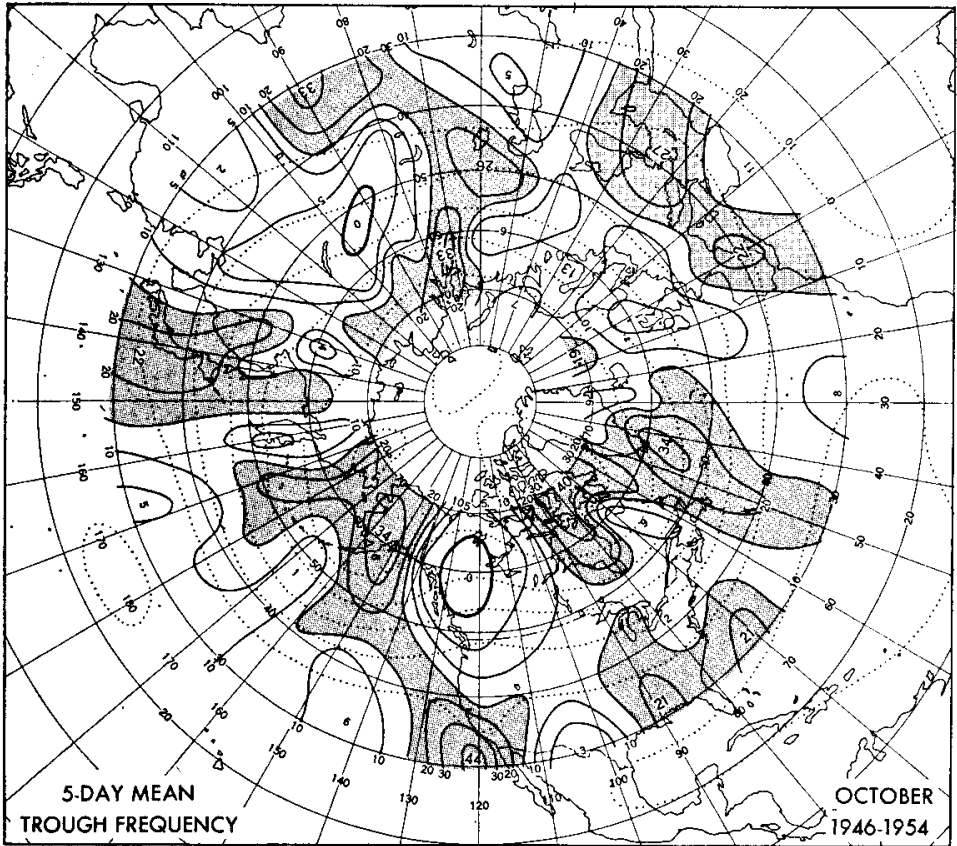

FIGURE 37

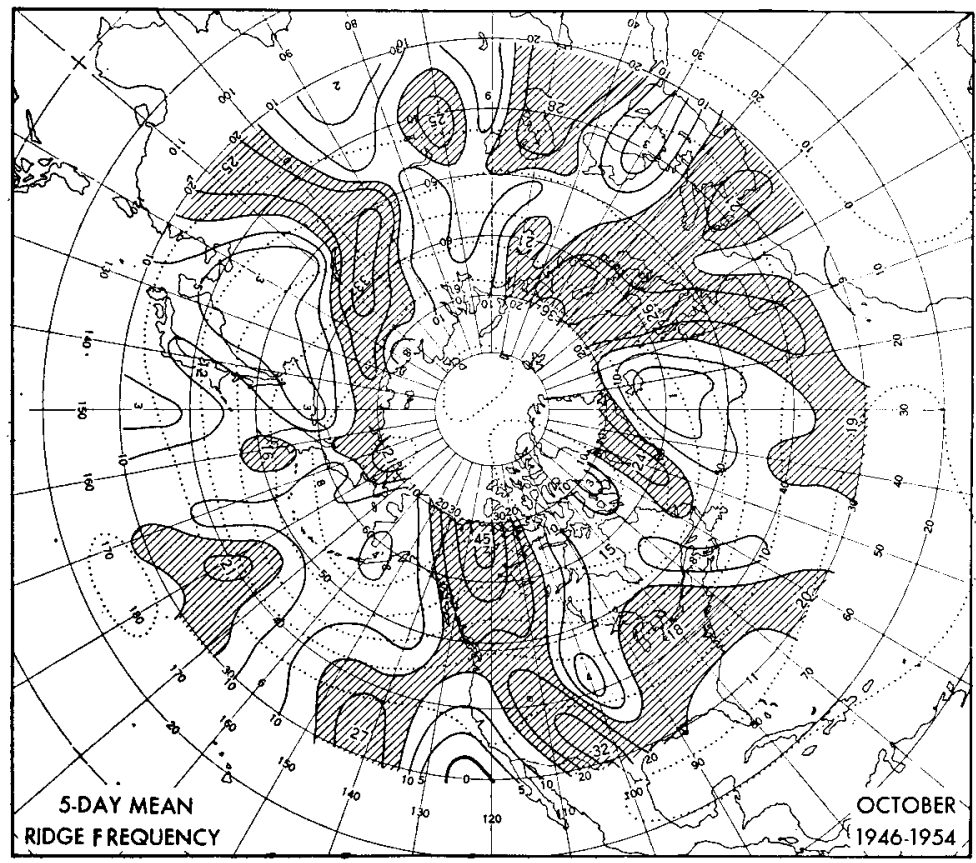

Figure 39.

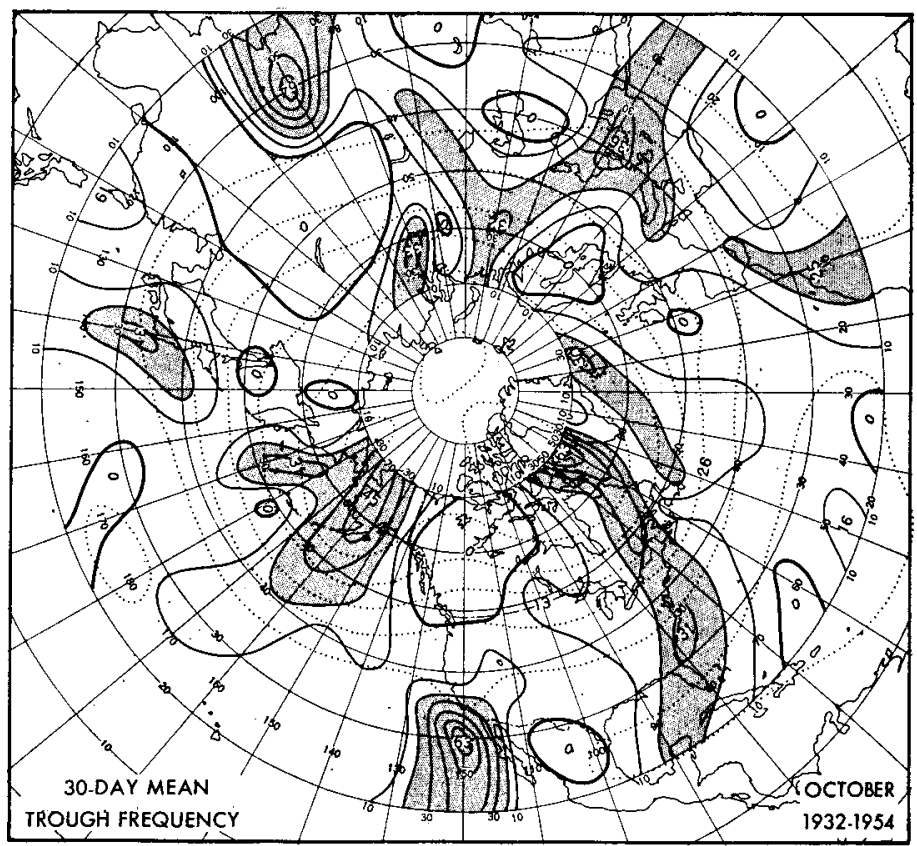

Figdre 38.

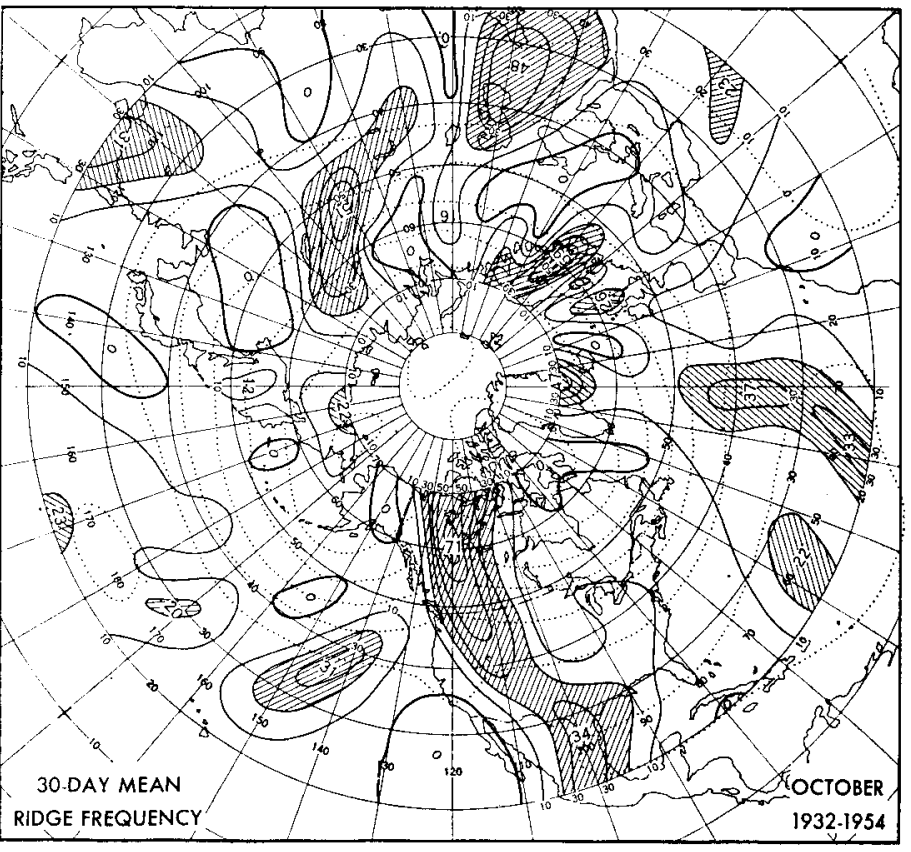

FrgURe 40. 


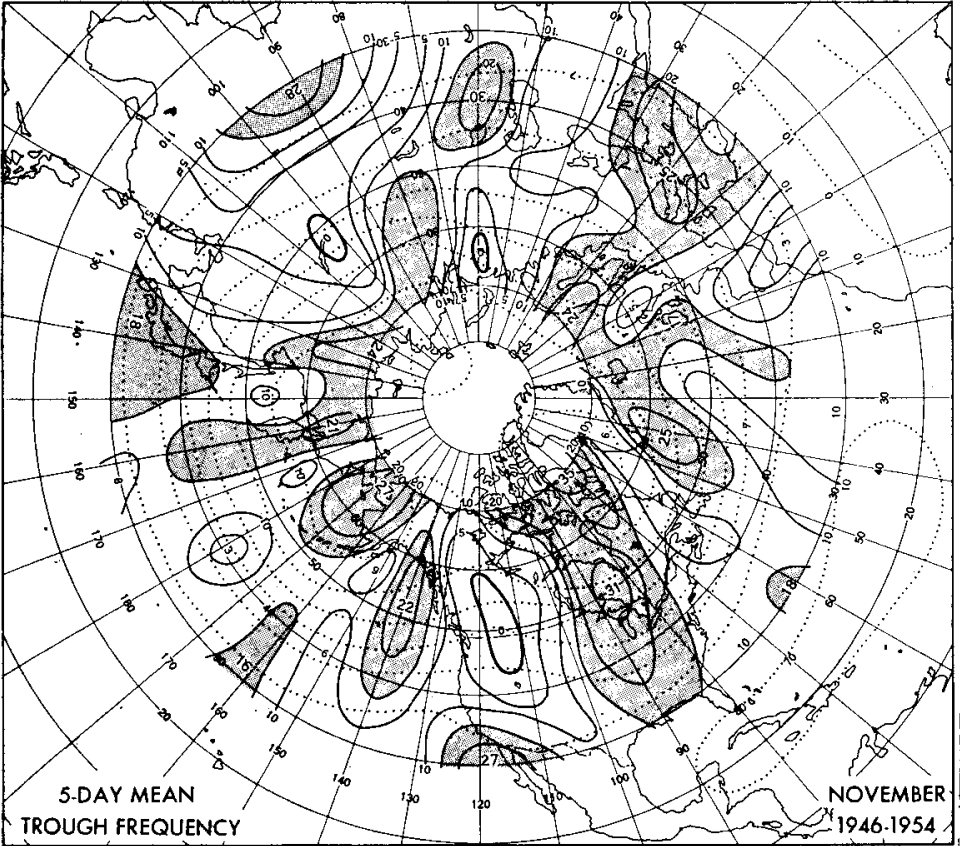

FIgURe 41 .

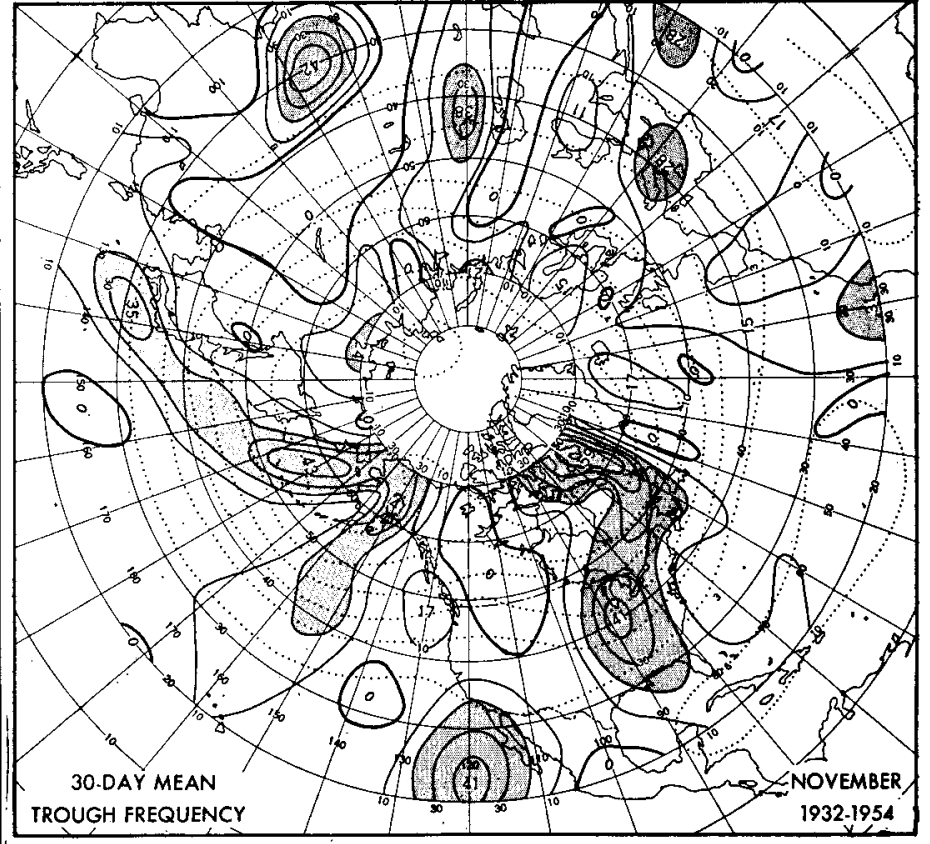

Frgure 42.

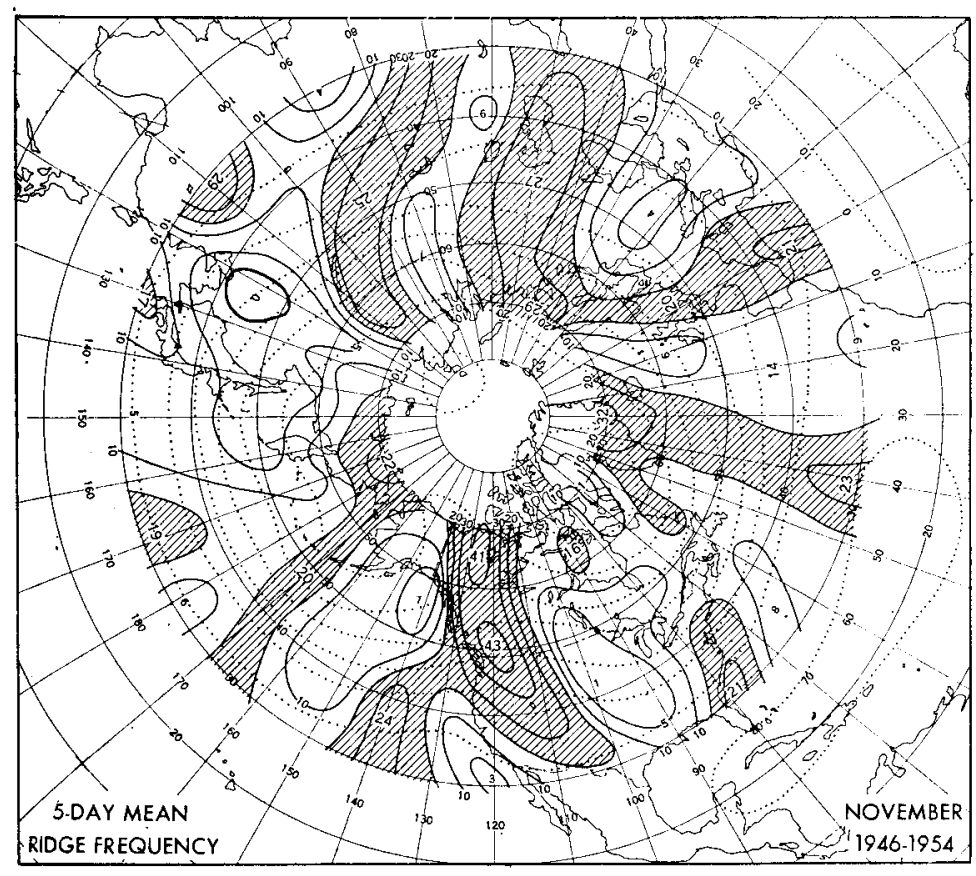

Figure 43.

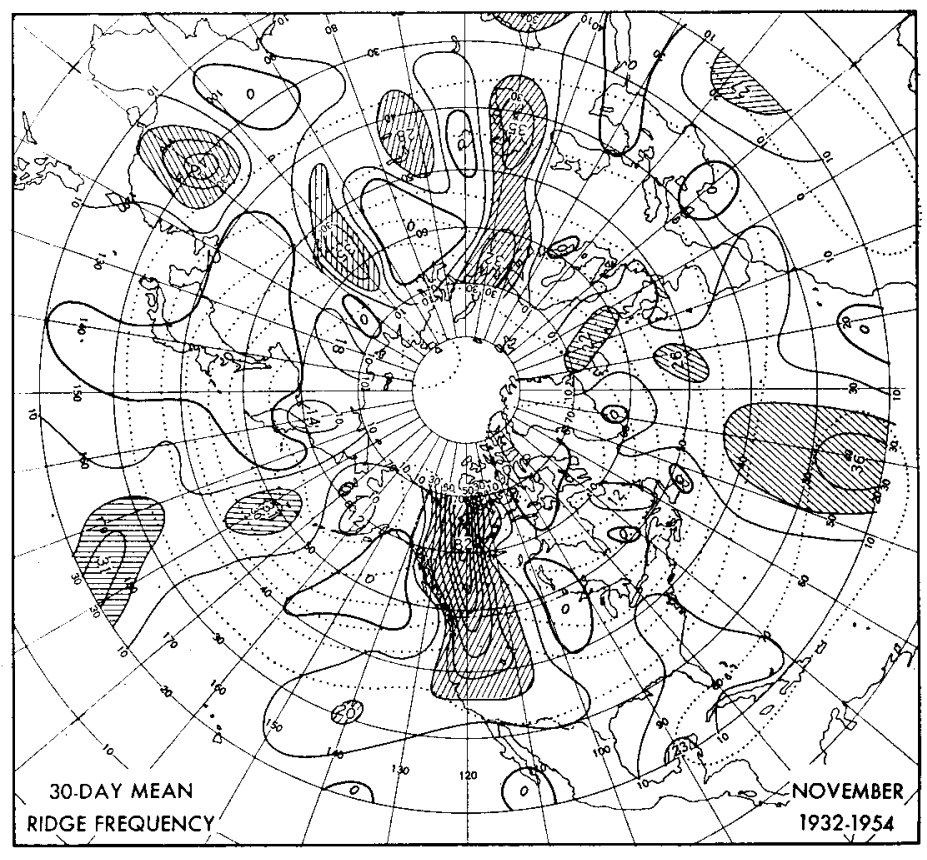

FigURE 44. 


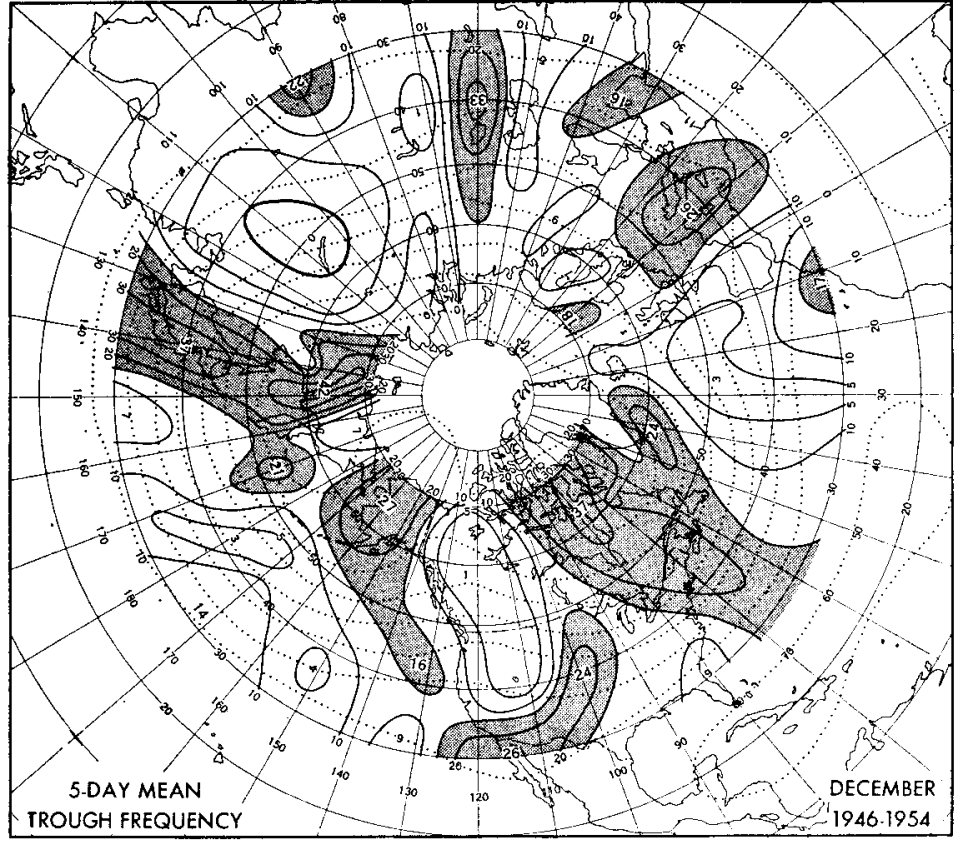

Figure 45

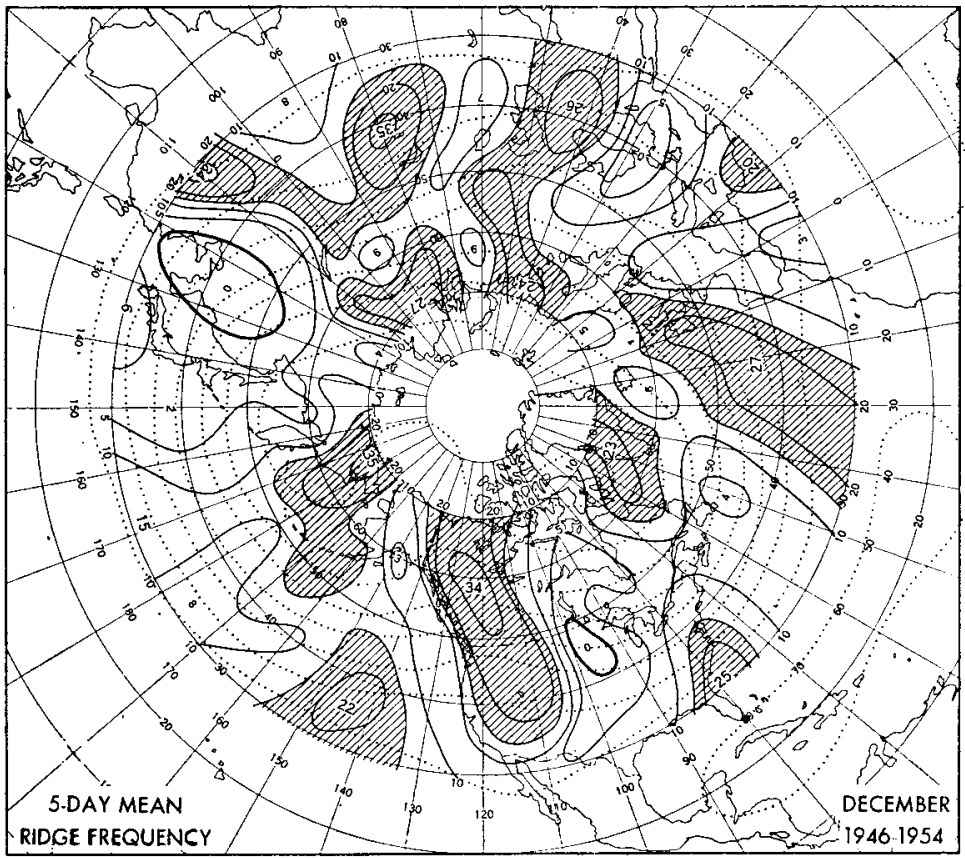

Figure 47.

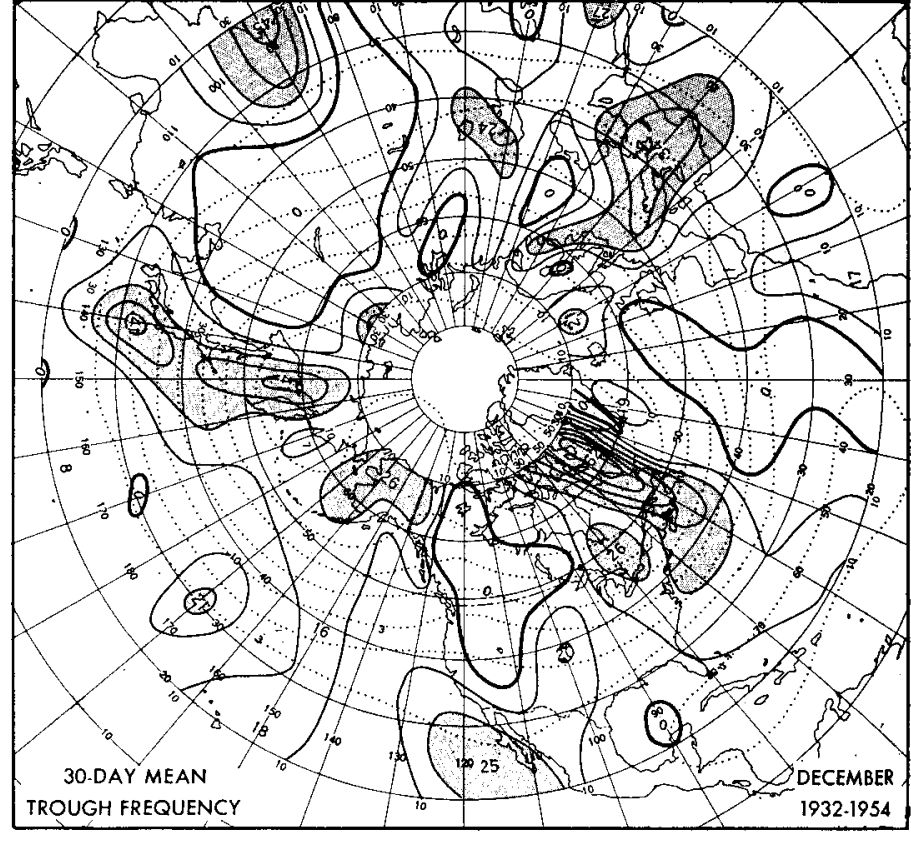

Figure 46

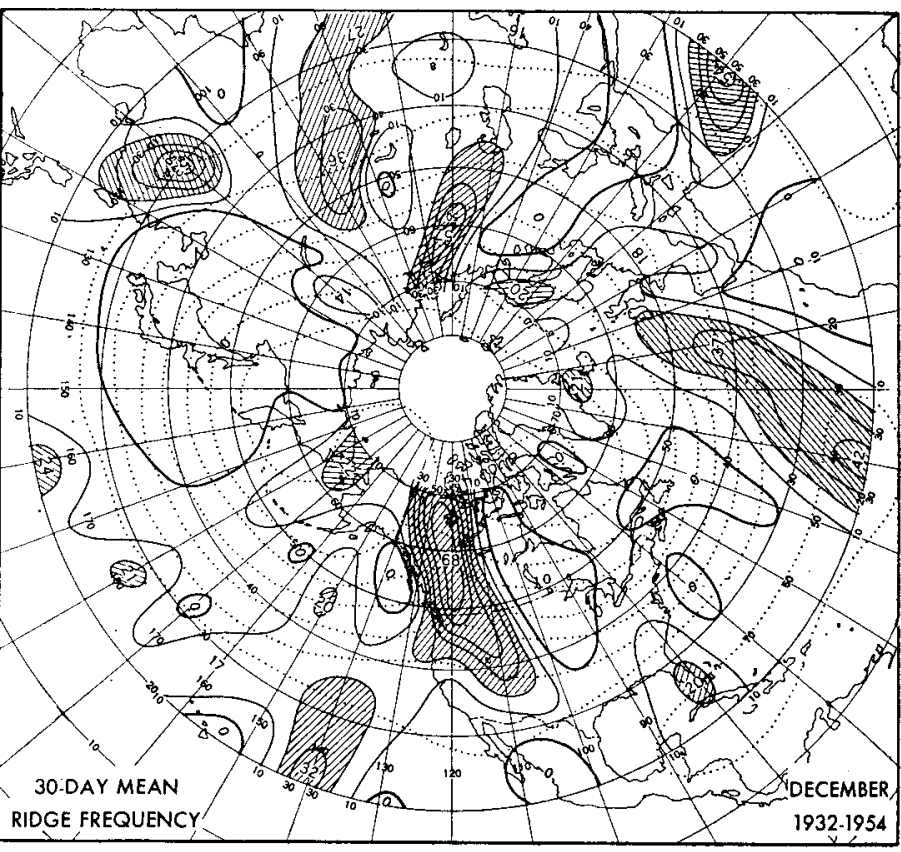

Figdre 48. 